REVIEW

\section{Directly transmitted unbalanced chromosome abnormalities and euchromatic variants}

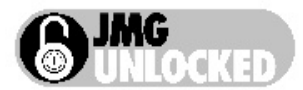

This article is available free on JMG online via the JMG Unlocked open access trial, funded by the Joint Information Systems Committee. For further information, see http://jmg.bmijournals.com/cgi/content/ full $/ 42 / 2 / 97$

J Med Genet 2005;42:609-629. doi: 10.1136/jmg.2004.026955

In total, 200 families were reviewed with directly transmitted, cytogenetically visible unbalanced chromosome abnormalities (UBCAs) or euchromatic variants (EVs). Both the 130 UBCA and $70 \mathrm{EV}$ families were divided into three groups depending on the presence or absence of an abnormal phenotype in parents and offspring.

No detectable phenotypic effect was evident in $23 / 130$ (18\%) UBCA families ascertained mostly through prenatal diagnosis (group 1). In 30/130 (23\%) families, the affected proband had the same UBCA as other phenotypically normal family members (group 2). In the remaining 77/ $130(59 \%)$ families, UBCAs had consistently mild consequences (group 3). In the 70 families with established EVs of 8p23.1, 9p12, $9 q 12,15 q 11.2$, and 16p11.2, no phenotypic effect was apparent in 38/70 (54\%). The same EV was found in affected probands and phenotypically normal family members in 30/70 families (43\%) (group 2), and an EV co-segregated with mild phenotypic anomalies in only 2/ 70 (3\%) families (group 3). Recent evidence indicates that $\mathrm{EV}$ s involve copy number variation of common paralogous gene and pseudogene sequences that are polymorphic in the normal population and only become visible at the cytogenetic level when copy number is high.

The average size of the deletions and duplications in all three groups of UBCAs was close to $10 \mathrm{Mb}$, and these UBCAs and EVs form the "Chromosome Anomaly Collection" at http://www.ngrl.org.uk/Wessex/ collection. The continuum of severity associated with UBCAs and the variability of the genome at the subcytogenetic level make further close collaboration between medical and laboratory staff essential to distinguish clinically silent variation from pathogenic rearrangement.
$T$ he resolution of the light microscope means that conventional chromosome analysis is limited to the detection of imbalances greater than 2-4 Mb of DNA. Consequently, unbalanced chromosomal abnormalities (UBCAs) usually involve several megabases of DNA, and the great majority are ascertained because of phenotypic or reproductive effects that bring patients to medical attention. The more severely affected an individual, the more likely they are to be investigated, creating an ascertainment bias that does not reflect the full range of phenotypes that may be associated with imbalance of a particular chromosomal segment. In examining subsequent cases, clinicians will naturally tend to look for features already reported and, at the same time, new and unusual features are more likely to reach publication than the absence of previously reported characteristics. Thus, a publication bias may compound a pre-existing ascertainment bias.

Many structural UBCAs are unique in the literature, and the phenotype associated with a given imbalance may depend on a single individual examined at a particular age. As a result, it can take many years before the phenotype associated with a particular imbalance can be defined. However, directly transmitted chromosomal imbalances, where parents and offspring have the same unbalanced cytogenetic abnormalities, provide the means of assessing the phenotype in one or more individuals at different ages as well as the opportunity of judging whether a chromosomal imbalance is a pathogenic or coincidental finding.

These transmitted imbalances are of two contrasting kinds. Firstly, there are the classic UBCAs, in which the copy number of multiple genes is either reduced or increased by one copy as in a deletion or duplication. An increasing number of exceptions to the rule that UBCAs result in significant phenotypic consequences have been reported in families ascertained for "incidental" reasons such as prenatal diagnosis because of maternal age. Secondly, there are the "euchromatic variants" (EVs), which usually resemble duplications. In an increasing number of instances, these reflect copy number variation

Correspondence to:

Dr J C K Barber, Wessex

Regional Genetics

Laboratory, Salisbury District Hospital, Salisbury,

Wiltshire SP2 8BJ, UK;

john.barber@salisbury. nhs.uk
Received 8 September 2004

Revised 6 January 2005

Accepted 6 January 2005
Abbreviations: $\mathrm{CGH}$, comparative genomic

hybridisation; CNV, copy number variation; DCR, Down's syndrom critical region; EV, euchromatic variants; HAL, haploid autosomal length; PWACR, Prader-Willi critical region; TNDM, transient neonatal diabetes mellitus; UBCA, unbalanced chromosome abnormalities 
of segments containing genes and pseudogenes, which are polymorphic in the normal population and only reach the cytogenetically detectable level when multiple copies are present. These EVs segregate in most families without apparent phenotypic consequences. Here, 130 families with transmitted UBCAs are reviewed, ${ }^{1-106}$ together with a further 70 families ${ }^{107-143}$ segregating the five established euchromatic variants of $8 \mathrm{p} 23.1,{ }^{108} 9 \mathrm{pl} 2,{ }^{130} 9 \mathrm{q} 12(9 \mathrm{qh}),{ }^{113} 15 \mathrm{ql} 1.2,{ }^{144}$ and $16 \mathrm{p} 11.2 .{ }^{128}$

The 200 families with UBCAs or EVs have been reviewed with respect to the type of rearrangement, size of imbalance, ascertainment, mode of transmission, and the presence or absence of phenotypic effects. Many more cytogenetic and subcytogenetic UBCAs and EVs are being identified now that higher resolution techniques are being used for routine constitutional analysis including high resolution molecular cytogenetics $^{145-147}$ and array comparative genomic hybridisation (CGH). ${ }^{148} 149$ Cytogenetically detectable anomalies with little or no phenotypic effect have previously been reviewed only in book form, ${ }^{150}{ }^{151}$ and the data from this review have been placed on a web site as the "Chromosome Anomaly Collection" (http://www.ngrl.co.uk/Wessex/collection.html).

\section{METHODS}

The contents of this review have been accumulated over time and are thought to contain the majority of documented transmitted UBCAs and EVs. However, there is no systematic way of searching the literature for transmitted anomalies, thus no claim can made that this review is comprehensive.

\section{Criteria for inclusion}

Families were selected on the basis of the direct vertical transmission of euploid autosomal UBCAs, or EVs from parent to child. As a result, aneuploid karyotypes were excluded, with the exception of a number of unbalanced tertiary monosomies resulting in transmitted karyotypes with 45 chromosomes. Satellited autosomes have not been included but are reviewed elsewhere. ${ }^{152}$ Supernumerary marker and ring chromosomes were excluded because of the confounding effects of a high degree of mosaicism on the phenotype. ${ }^{153-155}$ Transmitted imbalances of the sex chromosomes were also excluded because of the confounding effects of $\mathrm{X}$ inactivation in females.

\section{Groups}

The UBCA and EV families were divided into three major groups depending on the presence or absence of a detectable phenotypic effect in offspring, parents or both (table 1). Group 1: families in which transmitted UBCAs or EVs had no apparent phenotypic consequences in probands, parents and other family members; group 2: families in which the same UBCA or EV was found in affected probands as well as phenotypically normal parents and other family members; and group 3: families in which the same UBCA or EV was found in affected probands as well as affected parents and other family members.

\section{Phenotypic normality}

Individuals were considered phenotypically affected when any type of phenotypic anomaly was mentioned even if the aetiological role of the chromosome abnormality in the same individual is questionable. It is acknowledged that individuals in a given family may not have necessarily been examined by clinical genetic staff, but patients were presumed normal unless otherwise stated.

\section{Size of imbalances}

Wherever stated, estimates of the size of the imbalances derived by the authors of the relevant papers were used. Elsewhere, the size of each imbalance was estimated by measuring the proportion of the normal chromosome represented by the deleted or duplicated material on high resolution standardised idiograms and multiplying by the \% haploid autosomal length (HAL) of the chromosome concerned. ${ }^{156}$ The \% HAL was converted to Mb by multiplying by the $2840 \mathrm{Mb}$ estimated length of the human genome. ${ }^{157}$

\section{RESULTS}

The review covers 200 families in which 130 had transmitted UBCAs and 70 had transmitted EVs.

\section{Transmitted unbalanced chromosome abnormalities}

The location and extent of the UBCAs is illustrated in fig 1 , and details of the 130 UBCA families in groups 1, 2, and 3 are listed in Appendices 1, 2, and 3. Table 1 provides a summary of the ascertainment and the sex of the transmitting parents in each group and table 2 summarises the size of the imbalances.

The 130 families contained 374 UBCA carrying individuals with 111 different transmitted autosomal rearrangements involving 20 of the 22 autosomes, the exceptions being chromosomes 12 and 17. Chromosomes 5, 8, and 18 were the most frequently involved. Independent confirmation by FISH or molecular methods had been obtained in more than half $(87 / 130$ or $67 \%)$ of the families.

Over half these families (77/130 or 59\%) fell into group 3, in which a degree of phenotypic expression is found in both children and parents. Approximately a quarter fell into group $2(30 / 130$ or $23 \%)$, in which an affected proband has the same UBCA as an unaffected parent, and the remaining one fifth made up group 1 (23/130 or $18 \%)$, in which neither children nor parents are affected. Many of these imbalances were unique to the family concerned.

\begin{tabular}{|c|c|c|c|c|c|c|c|c|c|c|c|}
\hline \multirow[b]{2}{*}{ Group } & \multirow[b]{2}{*}{ NoF } & \multirow[b]{2}{*}{ NCo } & \multirow[b]{2}{*}{ Con } & \multicolumn{5}{|c|}{ Ascertainment } & \multicolumn{3}{|c|}{ Mode } \\
\hline & & & & PD & PA & MC & I & Other & M & $\mathbf{P}$ & B \\
\hline 1 (UBCAs) & 23 & 66 & 17 & 19 & 0 & 2 & 1 & 1 & 15 & 5 & 3 \\
\hline 2 (UBCAs) & 30 & 78 & 17 & 1 & 25 & 0 & 1 & 3 & 19 & 9 & 2 \\
\hline 3 (UBCAs) & 77 & 230 & 53 & 4 & 71 & 1 & 0 & 1 & 58 & 12 & 7 \\
\hline Totals & 130 & 374 & 87 & 24 & 96 & 3 & 2 & 5 & 92 & 26 & 12 \\
\hline 1 (EVs) & 38 & 94 & 15 & 29 & 0 & 4 & 0 & 4 & 18 & 17 & 3 \\
\hline 2 (EVs) & 30 & 84 & 15 & 0 & 31 & 0 & 0 & 0 & 13 & 9 & 8 \\
\hline 3 (EVs) & 2 & 6 & 1 & 0 & 2 & 0 & 0 & 0 & 1 & 1 & - \\
\hline Totals & 70 & 184 & 31 & 29 & 33 & 4 & 0 & 4 & 32 & 27 & 11 \\
\hline
\end{tabular}

NoF, number of families; NoC, number of carriers; Con, confirmed with an independent technique; PD, prenata diagnosis; PA, phenotypic abnormality; MC, miscarriages; I, Infertility; M, maternal transmission; P, Paternal transmission; B, Both maternal and paternal transmission. 

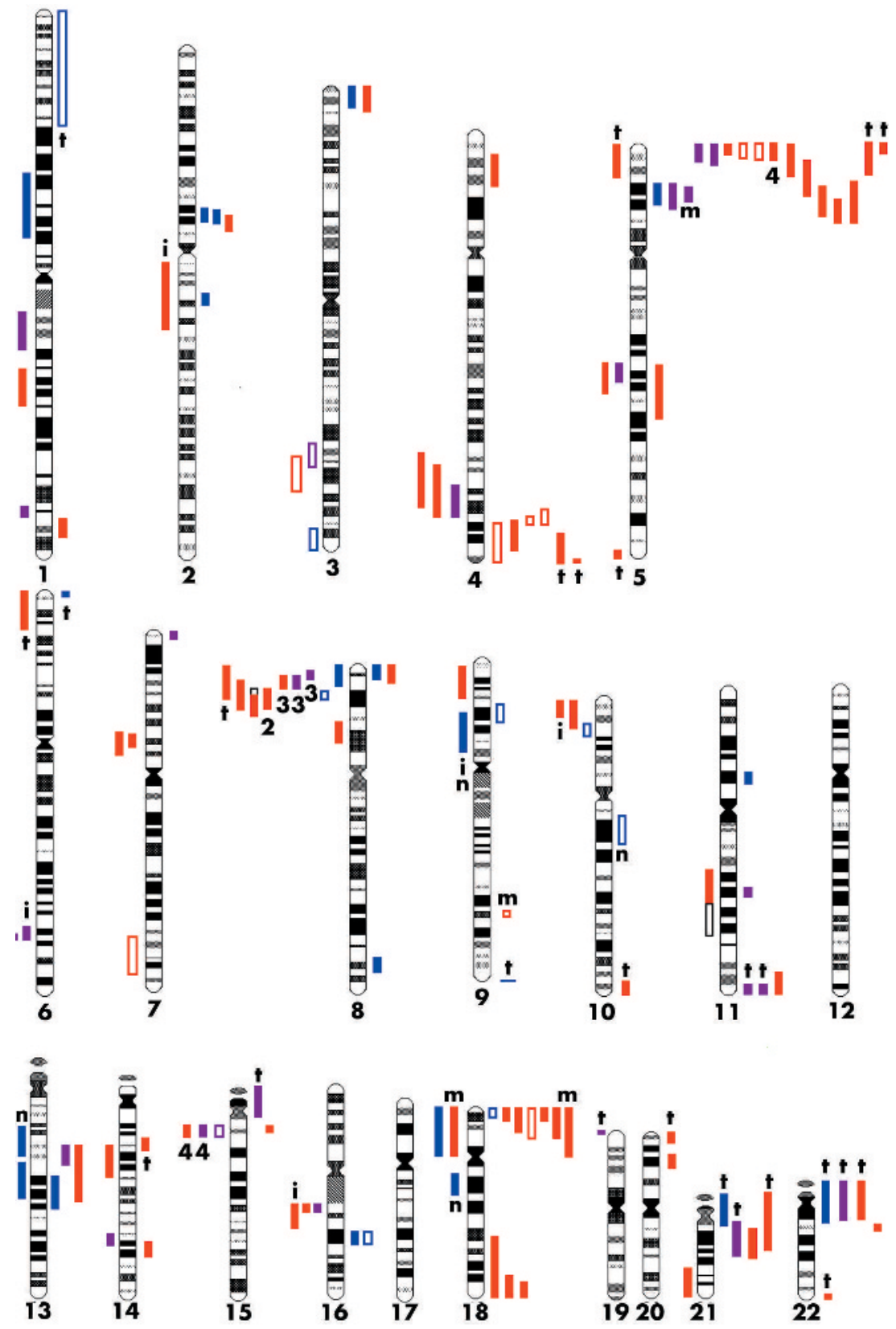

Figure 1 Idiograms with extent of duplications on the left hand side and deletions on the right hand side. Group 1 imbalances are in blue, group 2 in purple, and group 3 in red. Filled coloured bars are UBCAs from peer reviewed papers; open coloured boxes are from abstracts only. Open black boxes indicate alternative interpretations according to the authors concerned. Figures in black give the number of times independent families with the same rearrangement have been reported (for example, four times). t, translocation; i, insertion; m, mosaicism in a parent; $n$, the four exceptional UBCAs that were not directly transmitted.

Group 1: Phenotypically unaffected parents with the same unbalanced chromosome abnormality as their unaffected children

This group contained 23 families in which an unbalanced rearrangement had been directly transmitted from parent to child without phenotypic effect in 66 carriers. For completeness, four chromosomally unbalanced but phenotypically normal individuals were included from families in which direct transmission from an unbalanced parent had not been observed, ${ }^{158-161}$ making a total of 27 families. The majority (20/ $27 ; 74 \%$ ) of these families was ascertained at prenatal diagnosis because of maternal age (12/20). Of the remaining seven $(17 \%)$, three were ascertained for miscarriages, ${ }^{2}{ }^{9}{ }^{158}$ three because of the phenotype of a sibling 20160161 or daughter, ${ }^{159}$ and one for infertility. ${ }^{14}$

Of the 27 families, 14 had deletions, with an average size of $8.2 \mathrm{Mb}$ (range 4.2-16.0 Mb) (table 2), and of these, 12 consisted mainly of $G$ dark bands with or without some $G$ light flanking material. Seven families had transmitted interstitial duplications with an average size of $13.6 \mathrm{Mb}$ (range $3.4 \mathrm{Mb}$ to $31.3 \mathrm{Mb}$ ), of which only the duplications of $8 \mathrm{p} 22^{15}$ and $13 \mathrm{q} 14-\mathrm{q} 21^{17}$ were largely $\mathrm{G}$ dark bands. There were six families with unbalanced rearrangements, three of which had been transmitted from a parent with the same imbalance ${ }^{19-21}$ and three from a parent with a balanced form of the same rearrangement. ${ }^{159-161}$ 


\begin{tabular}{|c|c|c|c|c|}
\hline Group & Type & Number & Range (Mb) & $\begin{array}{l}\text { Average } \\
\text { size (Mb) }\end{array}$ \\
\hline \multirow[t]{2}{*}{1} & del & 14 & 4.2 to 16.0 & 8.2 \\
\hline & dup & 7 & 3.4 to 31.3 & 13.6 \\
\hline \multirow[t]{2}{*}{2} & del & 7 & 3.6 to 10.0 & 7.5 \\
\hline & dup & 19 & 2.0 to 11.4 & 6.1 \\
\hline \multirow[t]{2}{*}{3} & del & 38 & 2.7 to 30.8 & 10.9 \\
\hline & dup & 26 & 4.0 to 26.1 & 11.0 \\
\hline \multirow[t]{2}{*}{ Combined } & del & 59 & 2.7 to 30.8 & 9.9 \\
\hline & dup & 52 & 2.0 to 31.3 & 9.6 \\
\hline Total & del+dup & 111 & 2.0 to 31.3 & 9.8 \\
\hline
\end{tabular}

In the 23 families in which the UBCA had been directly transmitted from a parent to child, table 1 shows that the transmission was maternal in 15 families (71\%), paternal in in five, $(22 \%)$, and from both parents in three $(13 \%)$.

Group 2: Unaffected parents with the same autosomal imbalance as their affected children

This group contains 30 families with 78 carriers (Appendix $2)$. The majority $(25 / 30 ; 83 \%)$ were ascertained because of phenotypic abnormality (PA) in the proband. Of the remaining $5(17 \%)$, two were ascertained because of the phenotype of a sibling proband, ${ }^{30}$ one because of infertility, ${ }^{42}$ one because of leukaemia ${ }^{27}$ and one as a result of prenatal diagnosis following an abnormal ultrasound scan. ${ }^{31}$

Seven families had transmitted deletions with an average size of 7.5 Mb (range 3.6-10.0 Mb) (table 2) of which three largely involved the $\mathrm{G}$ dark bands 5pl4 and 1lq14.3. Nineteen families had transmitted duplications with an average size of $6.1 \mathrm{Mb}$ (range $2.0-16.3 \mathrm{Mb}$ ) of which the duplications of $4 \mathrm{q} 32^{30}$ and $8 \mathrm{p} 23.2^{32}$ were mainly G dark. Three families had transmitted unbalanced translocations.

Table 1 shows that exclusively maternal transmission was seen in 19/30 families (63\%) of families, paternal in $9 / 30$ $(30 \%)$, and from both in $2 / 30(7 \%)$.

Group 3: Affected parents with the same autosomal imbalance as their affected children

This group contains 230 carriers from 77 families (Appendix 3). Of 77 families, 71 (92\%) were referred for phenotypic abnormalities in the proband, which were, in most cases, reflected to a lesser or greater extent in other carriers from the same family.

Four of the 77 families (5\%) were ascertained through prenatal diagnosis; two of these because of maternal age, ${ }^{58} 91$ one because of abnormal ultrasound, ${ }^{67}$ and one because of a previous son with mental retardation. ${ }^{65}$ A single family was investigated because of miscarriages ${ }^{106}$ and a single family because of Prader-Willi syndrome in the proband..$^{33}$

Thirty-eight families out of 77 (49\%) had deletions with an average size of $10.9 \mathrm{Mb}$ (range 2.0-30.8 Mb). Twenty-seven families (35\%) had transmitted duplications with an average size of $11.0 \mathrm{Mb}$ (range 4.0-26.1). The remaining 12 (16\%) had transmitted unbalanced translocations of which 4 were insertional.

Table 1 shows that exclusively maternal transmission was seen in 58/77 families (75\%) of families, paternal in $9 / 30(16 \%)$ and transmission from carriers of both sexes in 7/77 (9\%).

Group 1 and 2 UBCAs, especially those overlapping with Group 3

Brief summaries are provided here of all group 1 and 2 UBCA families. Group 3 families are included wherever group 3
UBCAs overlapped with group 1 and/or group 2 UBCAs (fig 1).

\section{$\operatorname{der}(1)(p 32$-pter)}

One unconfirmed monosomy of 1 p32 to pter was ascertained at prenatal diagnosis and also apparently present in the father. ${ }^{19}$ This UBCA, reported in abstract, is impossible to reconcile with a normal phenotype, as even small imbalances of distal $\mathrm{lp}$ are associated with a recognisable chromosomal syndrome. ${ }^{162}$

\section{dup(1)(p21-p31)}

This large group 1 duplication was ascertained at prenatal diagnosis for maternal age. The duplication was found in the phenotypically normal mother, and the outcome of pregnancy was normal at term. ${ }^{13}$

\section{$\operatorname{dup}(1)(q 11-q 22)$}

This group 2 family was ascertained in a phenotypically normal boy of 9 with lymphadenopathy. ${ }^{27}$ A constitutional duplication of proximal lq was found in this boy, his phenotypically normal mother and his elder sister, neither of whom had lymphoma or leukaemia.

\section{$\operatorname{dup}(1)(q 42.11-q 42.12)$}

This group 2 family was ascertained in a boy who fed poorly and was in the 10th centile for growth..$^{28}$ The duplication had arisen de novo in the phenotypically normal mother and, by the age of 3 years, the boy's stature was in the 25 th centile when correlated with the height of his parents.

\section{del(2)(p12-p12)}

Two group 1 families with deletions of 6.1 Mb and 6.7 Mb within $G$ dark 2 pl2 were both ascertained at prenatal diagnosis. ${ }^{1}$ At least 13 loci including a cluster of six pancreatic islet regenerating genes were deleted. The pregnancies had normal outcome at birth and there were no other apparent phenotypic consequences in six other deletion carriers. It was proposed that segmental haplosufficiency may be associated with low gene density, especially where genes within a cluster on the normal homologue may compensate for each other, or genes of related function are present on other chromosomes. ${ }^{25}$ An overlapping $7.5 \mathrm{Mb}$ group 3 deletion extended into the gene rich part of 2pl1.2 and was found in a girl with speech delay and in her mother, who has expressive language difficulties (patients $25^{147}$ and $3^{1}$ ). Both had mild dysmorphic features.

del(2)(q13-q14.1)

A group 1 family was ascertained because a woman of 38 years had three early miscarriages. The deletion spanned $7 \mathrm{cM}$ from YAC $791 \mathrm{f} 4$ to YAC $676 \mathrm{~d} 2$. The consultand and her phenotypically normal mother had the same deletion, but the mother had no history of miscarriage. ${ }^{2}$

\section{del(3)(p25-pter)}

A terminal group 1 deletion with a 3p25.3 breakpoint was ascertained at prenatal diagnosis in a fetus and phenotypically normal mother. ${ }^{3}$ In contrast, in a group 3 family, an affected boy and his less severely affected mother had features consistent with 3 p-syndrome. ${ }^{46}$ It was suggested that the 3p25.3 breakpoint was distal to the genes responsible for $3 p$-syndrome. ${ }^{3}$ However, this could also be an example of non-penetrance of a chromosomal deletion, as haploinsufficiency of the $C A L L$ gene is thought to give rise to mental impairment and this gene should lie inside the deletion at $3 \mathrm{p} 26.1 .^{163}$

\section{$\operatorname{dup}(3)(q 25-q 26)$}

A group 2 family contained two sisters with congenital heart disease, mild developmental delay, dysmorphic, features and 
a dup(3)(q25q25). ${ }^{29}$ The same duplication was present in the normal father, grandmother, and greatgrandmother. The authors suggested a paternal imprinting effect, but this region of chromosome 3 is not known to be imprinted. A group 3 family with a larger overlapping dup(3)(q25.3q26.2) was independently ascertained once with congenital heart disease and once with microcephaly. ${ }^{78}$ These families suggest that the phenotype associated with duplication of 3q25 can extend into the normal range or that $3 \mathrm{q} 25$ contains a dosage sensitive locus that gives rise to heart disease with variable penetrance.

$\operatorname{dup}(3)(q 28 q 29)$

A group 1 family was ascertained at prenatal diagnosis for maternal age and found in the phenotypically normal father and an older sibling. ${ }^{12}$ A submicroscopic duplication of 3 q29 was ascertained in siblings with moderate mental retardation and dysmorphic features ${ }^{164}$ but was also present in the phenotypically normal mother and sister.

$\operatorname{dup}(4)(q 31-q 32)$

A group 3 family with a duplication of 4q31.1-q32.3 was ascertained in a mildly affected child and his mother, who were both developmentally delayed. ${ }^{79}$ This prompted Maltby et $a l^{30}$ to report a smaller group 2 duplication of $4 \mathrm{q} 32$ ascertained because of trisomy 21 in the proband. The duplication carrying sister had sensorineural deafness and the mother had no obvious clinical problems. The authors concluded that there were insufficient consistent findings to suggest a clinical effect, but this family also suggests that overlapping duplications centred on $\mathrm{G}$ dark 4q32 have a variable phenotype that can extend into the normal range. Few clinical details of the group 3 family of Van Dyke ${ }^{77}$ were given.

\section{del(5)(p 15-pter) terminal}

There were two group 2 deletions of 5 p15.3 and 10 group 3 monosomies of this region. The group 2 families had microcephaly, a cat-like cry and developmental delay, but not the severe delay and facial features of cri du chat syndrome associated with deletions of 5p15.2. ${ }^{22}$ There were four affected children in these group 2 families, but the carrier parent was apparently normal in each case. "Atypical" cri du chat syndrome in parents and children has also been described..$^{51-55}$ These families suggest a variable phenotype that can extend into the normal range but is more often characterised by speech delay, occasional deafness, and low to normal intelligence.

\section{del(5) (p13-p 15) interstitial}

There were one group 1 and two group 2 deletions of 5 pl4 itself as well as four larger overlapping group 3 deletions. The group 1 deletion of almost all 5pl4 was ascertained at prenatal diagnosis and found in a total of six normal carriers. $^{423}$ The G dark 5pl4.1-5pl4.3 group 2 deletion ascertained in a patient with a peroxisomal disorder was thought to be an incidental finding, as this condition had not previously been associated with any case of $5 p$ deletion. ${ }^{10}$ In a more recent family, ${ }^{23}$ a non-mosaic deletion contained within $5 \mathrm{pl} 4$ was found in a proband with microcephaly, seizures, and global developmental delay; the phenotypically normal father had the same deletion in blood, but only $1 / 500$ fibroblasts. Nevertheless, given the eight carriers in the other two $5 \mathrm{p} 14$ deletion families and the normal phenotype of the father, it seems likely the proband in this family represents ascertainment bias rather than variable expression of a phenotype associated with this deletion. By contrast, all the four overlapping group 3 deletions extended into adjacent $G$ light $5 \mathrm{p} 13,5 \mathrm{pl} 5$ or both. The phenotype varied within and between families from mild ${ }^{21}$ to variable ${ }^{57} 58$ and severe in the family of Martinez et al, ${ }^{56}$ which showed that cri du chat syndrome is compatible with fertility. $\operatorname{dup}(5)(q 15-q 22.1)$

A group 2 family with a dup(5)(q15q21) was ascertained at prenatal diagnosis because a cystic hygroma was found in one of two monzygotic twins using ultrasound. ${ }^{31}$ The authors concluded that the dup(5) could be a coincidental finding in view of the discordant abnormalities in the twins after delivery and the normal phenotype of the father. However, the father had suffered from epilepsy as a child and it is not unknown for cytogenetic abnormalities to have different consequences in monozygotic twins. ${ }^{165}$ A larger overlapping group 3 duplication also had a variable phenotype with mild dysmorphic features in mother and son but no mental retardation in the mother. ${ }^{80}$

dup(6)(q23.3-q24.3)

Both the group 2 families were ascertained with transient neonatal diabetes mellitus (TNDM) and have duplications that include the paternally imprinted $Z A C$ locus, which maps to 6q24.2. Imprinting explains the presence of TNDM in carriers with paternal duplications and the absence of TNDM in carriers with maternal duplications. While the proband and father in the family of Temple et $\mathrm{al}^{41}$ were discordant for TNDM, a degree of developmental delay in the father is probably due to this inserted duplication extending beyond band 6q24. An exceptionally mild phenotype was associated with an overlapping de novo 4-5 Mb deletion of 6q23.3-q24.2 that was of paternal origin. ${ }^{166}$

\section{del(8)(p23.1/2-pter)}

A group 1 family with a $\operatorname{del}(8)(\mathrm{p} 23.1$-pter) deletion was ascertained at prenatal diagnosis in a fetus and phenotypically normal father. ${ }^{5}$ The deletion breakpoint was believed to be more distal than the de novo deletions associated with developmental delay and heart defects. However, a group 3 family with an 8p23.1-pter deletion was ascertained in a boy of 7 years with mental slowness, behavioural problems, and seizures. ${ }^{59}$ His sister and father had minimal phenotypic abnormalities with borderline to normal intelligence. A de novo terminal deletion of 8p23.1-pter was ascertained in a girl with initial motor and language delays but average cognitive development and intellectual ability after close monitoring over a period of 5 years. ${ }^{167}$ These examples indicate that distal $8 p$ deletions are associated with a mild phenotype that can extend into the normal range.

\section{$\operatorname{del}(8)(q 24.13 q 24.22)$}

This group 1 family was ascertained because of a positive triple screen test. ${ }^{6}$ The phenotypically normal mother had the same deletion and a history of miscarriage and fetal loss. The pregnancy with the deletion resulted in a 26 week phenotypically normal stillbirth with significant placental pathology.

\section{$\operatorname{dup}(8)(p 23.1 p 23.3)$}

A group 1 family was ascertained for oligoasthenospermia, which was regarded as incidental in view of the normal fertility of a male carrier relative. ${ }^{14}$

$\operatorname{dup}(8)(\mathrm{p} 23.1 \mathrm{p} 23.2)$ : the abnormalities in the probands from three independent group 2 families with $2.5 \mathrm{Mb}$ duplications of G-dark 8p23.2 were inconsistent and not present in any of the carrier parents. ${ }^{32}$ The authors concluded that duplication of G-dark 8 p23.2 could probably be described as a benign cytogenetic variant.

$\operatorname{dup}(8)(p 23.1 p 23.1)$

There were 3 group 2 families and 3 group 3 families with cytogenetic duplications of 8 p23.1..$^{33}$ The abnormalities in the probands of the 3 group 2 families were inconsistent with each other and the same duplication was present in one of the parents in each family with no reported phenotypic abnormalities. In the 3 group 3 families, the first was ascertained with developmental delay while the carrier 
mother had short stature and abnormal feet. ${ }^{33}$ The second had Prader-Willi syndrome as well as an 8p23.1 duplication while the duplication carrier father had only atrial fibrillation. $^{33}$ The third group 3 family was a developmentally normal girl of 16 with a severe congenital heart defect. ${ }^{34}$ The authors proposed that her duplication interrupted the GATABinding Protein gene (GATA4), which maps to 8p23.1 and is known to give rise to heart defects when deleted. Her father had an isolated right aortic arch and his milder heart defect was attributed to mosaicism for the duplication. However, these cytogenetic duplications bear an uncanny resemblance to the EVs of 8p23.1 (see below), which have been shown to result from copy number expansion of a discrete domain within band 8p23.1 that does not contain the GATA4 locus. ${ }^{108} 109$ Thus, apparent duplications of 8 p23.1 have been associated with a wide variety of presentations but, as the content of many of these imbalances has not yet been determined, ascertainment bias may account for some of these observations and further analysis could distinguish genuine cytogenetic duplications from euchromatic variants of 8p23.1.

\section{dup(8)(p21.3-p23.1), (p22-p23.1) and (p21.3-p22 or} p22-p23.1)

Developmental or speech delay has been associated with duplications of 8p21.3-p23.1 in 2 group 3 families. ${ }^{86}$ Family 1 was ascertained with a complex heart defect but the mother and a sibling had the same duplication and no heart defects. Family 2 was ascertained for speech delay in a girl who had an IQ of 71 at age 6 and minor facial anomalies. Her carrier sister also had speech delay as well as a heart defect and mild facial dysmorphism. The normal phenotype in her father was attributed to mosaicism for the duplication, which was present in 6/24 cells. The authors concluded that this duplication is associated with mild to moderate delay without significant or consistent clinical features. A similar phenotype was reported in the group 3 duplications of $8 \mathrm{p} 22-\mathrm{p} 23.1 .^{85} 87$

$\operatorname{dup}(8)(p 22-p 22)$

A group 1 family with a small, "euchromatic expansion" of distal 8p22 was ascertained at prenatal diagnosis, confirmed with CGH and found in the phenotypically normal mother and grandfather. ${ }^{15}$ Overlapping de novo duplications of $8 \mathrm{p} 22$ p23.1 were recently reported using high resolution CGH in six families and thought to have Kabuki make-up syndrome ${ }^{168}$ but these observations have not been replicated by others. ${ }^{169}$

$\operatorname{del}(9)(p 12.2 p 22.1)$

A group 1 family was ascertained at prenatal diagnosis for maternal age when this deletion was found in the fetus as well as the phenotypically normal father and grandmother. ${ }^{7}$

dup (9)(p 12-p21.3)

A neonate ascertained with cri-du-chat syndrome had a deletion of chromosome 5 derived from her father who had an unbalanced insertional duplication of 9p12-p21.3. ${ }^{159}$ The estimated size of the duplication was $21 \mathrm{Mb}$ including approximately 280 genes. The balanced ins $(5 ; 9)(\mathrm{pl} 13.3 ; \mathrm{p} 12 \mathrm{p} 21)$ form of this insertion was present in the proband's grandmother and uncle.

$\operatorname{del}(10)(q 11.2-q 21.2)$

This deletion was found in the clinically normal 29 year old male partner of a couple referred for recurrent miscarriages. ${ }^{158}$ A patient with an overlapping de novo deletion had normal physical and psychomotor development until the age of 6 but subsequently developed symptoms of Cockayne syndrome. As the excision repair gene (ERCC6) associated with the autosomal dominant type II Cockayne syndrome has been mapped to band 10q21.1, it seems that deletion of proximal $10 \mathrm{q}$ is compatible with a normal phenotype but only if the ERCC6 locus is excluded or non-penetrant. dup (10)(p 13-p 14)

This group 1 family was ascertained at prenatal diagnosis in a family with a history of heart disease. ${ }^{16}$ The duplication was found in the fetus with normal outcome at birth, the phenotypically normal mother and a further child who had Tetralogy of Fallot (TOF). Other family members had TOF without the duplication of 10p13 and the authors concluded this is a duplication without phenotypic consequences.

\section{dell 11$)(q 25$-qter)}

The der(11)t(11;15) Group 2 family was ascertained for infertility. ${ }^{42}$ No phenotypic anomalies were reported in either the proband or his father but $61 \%$ of spermatocytes in the proband had XY multivalent contact at prophase suggesting a causal connection between the unbalanced translocation in the son despite the evident fertility of his father. Unpublished observations from this laboratory include another group 2 deletion of most of 11q25 ascertained in a boy of 6 with developmental delay (especially speech) but no heart defect. His phenotypically normal father had the same deletion. The larger overlapping group 3 deletion of 11q14.2-qter ${ }^{61}$ was ascertained in a child of nearly 3 with developmental delay. She also had a VSD but a heart defect was not suspected in the mother. Until more of these deletions have been mapped at the molecular level, it is impossible to say whether the phenotypically normal family members with 11q25 deletions are examples of segmental haplosufficiency or a variable phenotype that extends into the normal range. A second group 2 family in which an unbalanced der(11)t(11;22) translocation is dealt with under $\operatorname{del}(22 \mathrm{q})$ below. ${ }^{43}$

del(13)(q14q14), dup(13)(q14.1q21.3) and dup(13)(q13q74.3)

A group 2 family with a deletion of 13q14 was ascertained with retinoblastoma. ${ }^{26}$ A larger overlapping group 3 deletion was associated with both retinoblastoma and dysmorphic features in a mother and child. ${ }^{62}$ As retinoblastoma is recessive at the cellular level, the lack of a 'second hit' is likely to explain the absence of retinoblastoma in the mother of the first family. ${ }^{26}$ In a third family, unbalanced segregation of a balanced maternal ins $(20 ; 13)(\mathrm{pl} 2 ; \mathrm{q} 13 \mathrm{q} 14.3)$ insertion resulted in deletion of 13q13-q14.3 and retinoblastoma in the proband. ${ }^{160}$ However, the proband's older sister had a duplication of the same segment and was clinically normal as was a younger sister at birth.

del(13)(q21q21) and dup(13)(q14-q21)

A group 1 del(13)(q21q21) was ascertained for recurrent miscarriages in a phenotypically normal family. ${ }^{9}$ An overlapping group 1 dup(13)(q14-q21) was detected at prenatal diagnosis when an extra 13q14 LIS1 signal was seen in interphase cells and only a partial duplication of chromosome 13 in metaphases. ${ }^{17}$ The same duplication was present in the mother who was clinically normal apart from hyposomia.

dup (13)(q14-q21) and dup (13)(q13-q14.3)

See del(13) entries above.

dup (14)(q24.3-q31)

In a group 2 family, imprinting might have explained the normal phenotype in the father of a girl who had developmental delay, microcephaly and dysmorphic features at the age of $3 \frac{1}{2}$ effects. ${ }^{34}$ However, grandmaternal transmission could not be established as the father was adopted. In addition, the girl had only a few of the features recorded in previous cases of pure $14 \mathrm{q}$ duplication. It is therefore impossible to be certain whether the $\operatorname{dup}(14)$ is the cause of the child's phenotype or an incidental finding in this family. 
$\operatorname{dup}(15)(q 11.2 q 13)$

There are at least five group $2^{35-39}$ and four group 3 families $^{35} 93$ with transmitted interstitial duplications that include the PWACR. The imprinted nature of this region explains the fact that children with developmental delay and/ or autism all had maternal duplications ${ }^{35-39}$ while the normal parents in three of these five families had duplications of grandpaternal origin. ${ }^{37-39}$ Both parents and children were affected in the four group 3 families $^{35}{ }^{93}$ but two out of three unaffected grandparents again had duplications of grandpaternal origin. ${ }^{35}$ However, one mother with a paternally transmitted duplication had mild developmental delay and it is therefore possible that the phenotype associated with paternal duplications can extend into the mildly affected range. Bolton et $\mathrm{al}^{35}$ compared the phenotype of 21 individuals from 6 families and found that maternally transmitted dup(15)(q11.2q13) was associated with a variable degree of intellectual impairment and motor coordination problems but only one individual met the criteria for classic autism.

\section{del(16)(q21q21)}

Two independent group 1 families were both ascertained at prenatal diagnosis with deletions of G-dark 16q21. ${ }^{10-11}$ There were two other phenotypically normal carriers in each family. The family of Witt et $\mathrm{al}^{11}$ has previously been contrasted with an adult patient who had a cytogenetically identical deletion of $16 \mathrm{q} 21^{170}$ but many of the features of 16q- syndrome. ${ }^{171}$

$\operatorname{dup}(16)(q 12.1 q 12.1),(q 11.2-q 12.1)$ and (q11.2-q13.1) Verma et $\mathrm{al}^{40}$ considered a duplication of $16 \mathrm{q} 12.1$ in an autistic child of $4 \frac{1}{2}$ and his clinically normal mother as an unusual variant. The overlapping duplications of q11.2-q12.1 and q11.2-q13.1 were consistently associated with developmental delay, speech delay, learning difficulties and behavioural problems ${ }^{21} 94$ while de novo adult cases have been associated with a more severe phenotype. ${ }^{172}$ In most of these families, the duplicated material is found within the major 16q11.2/16qh block of heterochromatin but these are clearly not analogous to the EVs of $9 \mathrm{q} 12 / 9 \mathrm{qh}$ (see below). It seems that duplications of proximal 16q can be severe but are more often associated with a variable cognitive phenotype that may exceptionally extend into the normal range.

\section{del(18)(cen-pter)}

There were a total of 7 families with transmitted deletions of $18 \mathrm{p}$ including a single group 1 family with a deletion of 18pl1.31-pter ${ }^{12}$ and 6 group 3 families with deletion breakpoints that ranged from pl1.3 $3^{65}$ to the centromere. ${ }^{70}$ The group 1 family was ascertained at prenatal diagnosis for a raised serum AFP and had the smallest deletion. The group 3 family of Rigola et $\mathrm{al}^{65}$ was ascertained at prenatal diagnosis because of a previous son with mental retardation. The authors concluded that the phenotype in their 18p11.3-pter deletion family was subtle as the mother had only mild mental retardation and minor congenital malformations. In another group 3 family, ${ }^{66}$ both the child and mother with del(18)(pll.21-pter) had short stature, mental retardation and ocular anomalies. By contrast, the group $3 \operatorname{del}(18)(p 11.2-$ pter) of Tonk and Krishna ${ }^{67}$ was ascertained because of abnormal routine ultrasound findings. A very dysmorphic fetus with features that included cyclopia was found after spontaneous delivery at 24 weeks gestation while the mother had mild mental retardation and some dysmorphic features but. Concordant phenotypes with many of the features of $18 p$ - syndrome were seen in the other three group 3 families with larger $18 \mathrm{p}$ deletions. ${ }^{68-70}$

\section{dup (18)(cen-pter)}

A group 1 family with a duplication of the whole of $18 p$ was ascertained at prenatal diagnosis following a raised serum
AFP. ${ }^{18}$ At 2 years of age, the child's development was normal and she shared bilateral short fifth fingers with her carrier mother and pre-auricular pits with her father. After reviewing 14 other cases, the authors concluded that duplication of $18 \mathrm{p}$ produced little if any phenotypic effect. By contrast, Moog et $\mathrm{al}^{95}$ ascertained a group 3 family with a duplication of the whole of $18 \mathrm{p}$ in a child with psychomotor delay, slight craniofacial anomalies and moderate mental retardation. The mother had the same duplication in $80 \%$ of cells and had been developmentally delayed. By the age of 26 , she had height and head circumference less than the $3^{\text {rd }}$ centile and "borderline" mental impairment. The father was also mentally retarded. The authors concluded that duplication of $18 \mathrm{p}$ is not a specific phenotypic entity but may be associated with non-specific anomalies and a variable degree of mental impairment. Thus, duplication of $18 \mathrm{p}$ has mild phenotypic consequences that can extend into the normal range.

$\operatorname{dup}(18)(q 11.2 q 12.2)$

This duplication was found in the fetus of a mother of 24 referred for prenatal diagnosis with a family history of Down's syndrome. ${ }^{161}$ The mother and her next child had a balanced ins(18)(p11.32;q11.2q12.2) insertion but a third child had the corresponding duplication and was phenotypically normal at three months of age.

$\operatorname{del}(21)(q 11.2-q 21.3),(p t e r-21 q 21.2),(p t e r-q 21)$

A group 1, group 2 and group 3 family were each ascertained as a result of Down's syndrome in the proband. In each family, tertiary monsomic forms of unbalanced translocations were found in two or more other family members. In the group 1 family, ${ }^{20}$ there were no reported phenotypic anomalies in four family members. However, it is possible that this fusion of $6 \mathrm{p}$ and $2 \mathrm{lq}$ involved no actual loss of coding material especially as de novo loss of subtelomeric $6 \mathrm{p}$ has been associated with mental retardation, dysmorphic features and a heart defect. ${ }^{163}$ In the group 2 family, an unbalanced 19;21 translocation with deletion of pter-q21.1 and a possible deletion of $19 \mathrm{p}$ was ascertained in a child because of Down's syndrome in a sibling proband. ${ }^{44}$ The child had only behavioural difficulties and the carrier mother was of average intelligence. In the group 3 family, four family members had a complex unbalanced 21;22 translocation and effective monosomy for 21q21.2-pter. ${ }^{104}$ This family had a consistently mild phenotype with developmental delay, learning disabilities and poor social adjustment. The only group 3 deletion of the 2 lq11.2-q21.3 region $^{75}$ was ascertained in a child with dislocation of the hips at 11 months of age. By the age of 5 he had motor and language delay and the mother had mild mental retardation. The authors concluded that psychomotor retardation is the only consistent feature of proximal $2 \mathrm{lq}$ deletion with a variable degree of expression of other minor anomalies. Roland et $\mathrm{al}^{75}$ also pointed out that more severe de novo cases have been reported as well as a de novo case with normal intelligence but poor motor skills. ${ }^{173} \mathrm{~A}$ duplication of proximal $2 \mathrm{lq}$ with normal phenotype has also been reported. ${ }^{174}$

\section{del(22)(q11.21-pter)}

In the group 1 family, an unbalanced tertiary monosomic $(9 ; 22)$ translocation was ascertained during prenatal diagnosis and found in three other family members. ${ }^{21}$ The $9 \mathrm{q}$ subtelomere was intact, but a diminished signal from BAC 609C6 indicated a 22q11.21 breakpoint and the loss of some coding material from proximal 22q. In the group 2 family, an unbalanced $\operatorname{der}(11) t(11 ; 22)$ tertiary monosomy was ascertained in a dysmorphic boy with a heart defect, his two siblings, and his mother. ${ }^{43}$ The phenotype could have resulted from the deletions of either llq25 and proximal 22 or both. As only one of the two siblings had a heart defect and the 
mother was clinically normal, the authors suggested that the unbalanced karyotype might be a coincidental finding in view of the variability of the phenotype. However, variable expression of heart defects is now well known in transmitted submicroscopic deletions of $22 \mathrm{q} 11.2^{101}{ }^{175}$ and suspected in 11 q25 deletions (see del(11)(q25-qter) above). In the group 3 family, an unbalanced der(4)t $(4 ; 22)$ translocation and monosomies of both $4 \mathrm{q} 35.2$-qter and proximal $22 \mathrm{q}$ were ascertained in a dysmorphic boy with a heart defect. ${ }^{101}$ The complete and partial Di George syndrome seen in the son and mother was attributed to the proximal 22q deletion, although heart defects have subsequently been described in other unbalanced submicroscopic translocation involving 4q. ${ }^{163}$

\section{Euchromatic variants}

The cytogenetic locations of the five major EVs are illustrated in fig 2, and the details of $70 \mathrm{EV}$ families in Appendices 4, 5, and 6. By contrast with the UBCA families, each of these EVs has been independently ascertained on multiple occasions. Of the 70 families, 38 were group 1 (54\%), 30 were group 2 $(43 \%)$, and only two were group $3(3 \%)$. Table 1 provides a summary of the ascertainment and sex of the transmitting parents in each group. The EVs of 8p23.1, 15q11.2, and $16 \mathrm{p} 11.2$ have been described as constitutional cytogenetic amplifications because they involve variable domains that are only detectable at the cytogenetic level when present in multiple copies. ${ }^{109120133177}$

Group 1 EVs: Phenotypically unaffected parents with the same EV as their unaffected children

This group contains 38 families with 94 carriers involving all five of the most common EVs established to date (Appendix $4)$. Of the 38 families, 30 were ascertained at prenatal diagnosis $(79 \%), 12$ of whom had undergone the procedure because of maternal age. Four families were referred for recurrent miscarriages and one for loss of a pregnancy, but it is difficult to reconcile this with phenotypically silent EV unless such variation predisposes to larger imbalances or non-disjunction of the same chromosome; this has not been

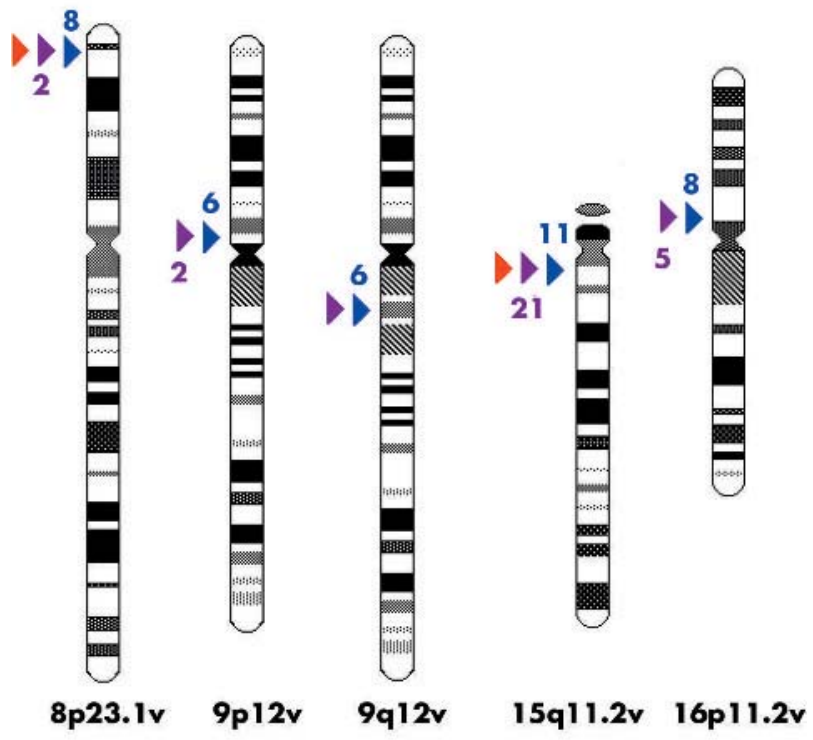

Figure 2 Idiograms with the position at which EVs occur marked by arrows. Group $1 \mathrm{EV}$ imbalances are in blue; group $2 \mathrm{EV}$ in purple, and group $3 \mathrm{EV}$ in red. Figures give the number of times independent families with the same rearrangement have been reported (for example, eight times). shown in any of the families listed here to date. Two families were investigated because of trisomy 21 in a relative and the final family was ascertained incidentally during a survey of newborns. ${ }^{113}$

Table 1 shows that exclusively maternal transmission was seen in 18 of the 38 families (47\%) of families, paternal in 17 $(45 \%)$, and transmission from both in three families $(8 \%)$.

Group 2 EVs: Unaffected parents with the same EV as their affected children

Appendix 5 contains 84 carriers from 30 families. All 30 were ascertained for dissimilar phenotypic abnormalities in the probands. One family was independently ascertained once in a male of 62 years with myelodysplasia ${ }^{139}$ and once in a child of 3 years with developmental delay and mild dysmorphic features. ${ }^{128}$ Six other family members were phenotypically normal and this child was later diagnosed with fragile $\mathrm{X}$ syndrome (Thompson, personal communication).

Table 1 shows that exclusively maternal transmission was seen in 13 of the 30 families (43\%), paternal in nine $(30 \%)$ and transmission from both in eight $(27 \%)$.

Group $3 \mathrm{EVs}$ : affected parents with the same EV as their affected child

There were only two families in this group (Appendix 6). In the first family, an 8p23.1 EV was associated with very mild dysmorphism in a mother and her two daughters; further family members were not available and the association of EV and phenotype remains questionable. ${ }^{142}$ In the second family, ${ }^{143}$ short stature cosegregated with a proximal $15 \mathrm{q}$ amplification variant that was later shown to involve multiple copies of the proximal $15 \mathrm{q}$ pseudogene cassette. ${ }^{176}$ Apart from short stature, the proband had slight hypotonia and a tendency to hyperphagia but no functional modification of the PWACR could be found. The authors concluded that this EV was probably not related to the child's phenotype. Transmission was maternal in both families.

\section{Group 1, 2, and 3 EVs especially where these} overlap with UBCAs

Brief summaries are provided of the group 1 and $2 \mathrm{EV}$ families with particular attention to those instances where group 1 and 2 EVs overlap with each other or with group 3 EVs (fig 2).

$8 p 23.1 v$

At least 11 families have been reported with this apparent duplication of 8p23.1 (8 in group $1 \mathrm{EV}, 2$ in group $2 \mathrm{EV}$ and 1 in group $3 \mathrm{EV})$. Twenty-five out of the 27 carriers in the first three reports were phenotypically normal..$^{108} 110111$ Similar findings were reported in two further families ${ }^{107}{ }^{129}$ while only minimal features were found in the single group 3 family. ${ }^{142}$ Williams et $a l^{110}$ found variation of $8 \mathrm{p} 23.1$ in a developmentally delayed boy of 18 months but his delay was said to be "spontaneously resolving" by the age of 2 years (Williams L, personal communication). Hollox et al ${ }^{109}$ used quantitative multiplex amplifiable probe hybridisation to show that the underlying basis of the duplication in three of these EV families was the increased copy number of a domain of at least $260 \mathrm{~kb}$ containing three defensin genes (DEFB4, $D E F B 103$, and DEFB104) and a sperm maturation gene (SPAG11). Semi-quantitative FISH indicated that an olfactory receptor repeat is also involved and a recent contig suggests that this domain is normally within the distal 8p23.1 OR repeat itself (REPD). ${ }^{177}$ Total copy number of this domain in normal controls varied between 2 and 7, whereas EV carriers had between 9 and 12 copies. Expression of DEFB4 was increased with copy number and, as the defensins encode cationic antimicrobial peptides, it has been suggested that increased copy number could enhance resistance to infection 
or modify the effects of Pseudomonas aeruginosa in cystic fibrosis. ${ }^{109}$ Copy number variation of a $1 \mathrm{Mb}$ domain that lies $7 \mathrm{Mb}$ from the telomere (CNP 45) has been detected in normal controls, ${ }^{178}$ but it is not certain that this coincides with the defensin EV, which is thought to lie at or adjacent to REPD at 7.5 Mb from the telomere. Tsai et $\mathrm{al}^{33}$ and Kennedy et $a l^{84}$ claim that duplications of $8 \mathrm{p} 23.1$ are associated with developmental delay and heart disease but have not mapped the extent of their duplications (see UBCA dup(8) (p23.1p23.1) above). Recent evidence submitted for publication $^{179}$ indicates that duplications and EVs of 8p23.1 resemble each other at the cytogenetic level but can be separated into two distinct groups: (a) genuine 8p23.1 duplications of the interval between the olfactory receptor repeats including the GATA4 gene and associated with developmental delay and heart defects; and $(b)$ EVs that involve increased copy number of the variable defensin domain only and do not have phenotypic conseqences.

$9 p 12 v$

There are at least eight families with this EV (six group l EVs and two group 2 EVs), which resembles a duplication of $G$ dark 9p12 and is negative when C banded. Webb et al ${ }^{12}$ described the extra material as being of "intermediate density" when G banded, noted how the extent of the extra material can vary when transmitted, and suggested that this $\mathrm{EV}$ is a homogeneous staining region. As $9 \mathrm{ql} 2 \mathrm{EVs}$ derive from a unit present in multiple copies in both $9 p$ and $9 q^{115} 180$ (see below), it is likely that the cytogenetic 9p EVs also reflect increased copy number of a variable domain by analogy with the 16p11.2 EVs (see below). It is possible that these coincide with the $9 \mathrm{p} 11$ and $9 \mathrm{q} 12$ polymorphisms identified by Sebat $e t$ al (CNPs 51 and 52). ${ }^{178}$

\section{$9 q 12 v / 9 q h v$}

There are at least seven families with this EV, which reflects extra $\mathrm{C}$ band negative, $\mathrm{G}$ dark material that is found within the major 9q12/qh block of heterochromatin (six group l EVs and one group $2 \mathrm{EV}$ ). The group 2 EVs had 9q13-q21 breakpoints, ${ }^{132}$ but resembles the other $9 \mathrm{q} 12 / \mathrm{qh}$ EVs at the cytogenetic level. YAC $878 \mathrm{e} 3$ hybridises to the extra material in the 9q12/qh EVs, and subclones of this YAC indicate that these EVs derive from a large unit present in multiple copies in both proximal 9p and juxtaheterochromatic 9q13. ${ }^{115}{ }^{180} \mathrm{~A}$ shared identity between subclones and expressed sequence tags suggests that this variation includes coding sequences. ${ }^{180}$ Sequences of this type may also underlie the unconfirmed claim that a separate type of $9 \mathrm{q} 12 \mathrm{v}$ chromosome exists with material derived from $9 \mathrm{q} 13-\mathrm{q} 21 .{ }^{151}$

The established 9q12 EVs are clearly not analogous to the extra euchromatic material found within the major 16pl1.2/ qh block of heterochromatin, which has so far always been a genuine duplication of proximal 16q (see UBCA dup(16) above).

\section{$15 q 71.2 v$}

At least 32 families have been reported with extra material within proximal 15q ( 10 group 1 EVs, 21 group 2 EVs, and a single group 3 EV family). These EVs resemble duplications or triplications and can be misinterpreted as a duplication of 15q11.2-q13 or even a deletion of the homologous 15. The underlying basis of this $\mathrm{EV}$ is variation in the copy number of a cassette of neurofibromatosis (NFI), immunoglobulin heavy chain $(\operatorname{IgH} D / V)$, gamma-aminobutyric acid type A5 subunit (GABRA5), and B cell lymphoma 8 (BCL8A) paralogous pseudogenes, ${ }^{120} 133176$ which map between the PWACR and the centromere. The NF1 pseudogene has 1-4 copies in controls and expands to 5-10 copies in EV carriers, while the $I g H D$ region has $1-3$ copies in controls and expands to 4-9 signals in the majority of EV carriers. ${ }^{120}$ This expansion has been described as constitutional cytogenetic amplification. ${ }^{123}$ Similar variation may be expected at the other sites to which NF-1 pseudogenes map including 2q21, 2q23-q24, $14 \mathrm{q} 11.2,18 \mathrm{pl} 1.2,21 \mathrm{ql} 1.2$, and $22 \mathrm{q} 11.2{ }^{181}$ It is likely that the $1.6 \mathrm{Mb}$ copy number polymorphism detected by Sebat et al ${ }^{178}$ in 15qll (CNP 69) coincides with the 15q11.2 EV cassette. The claim that a separate 15q12.2-q13.1 EV exists has not yet been confirmed with locus specific probes. ${ }^{151}$

\section{$16 p 11.2 v$}

There are at least 12 families in the literature (seven group 1 EVs and five group 2 EVs) with extra material within proximal 16p, which can resemble a duplication of $G$ dark 16p12.1. This EV also reflects increased copy number of another cassette of immunoglobulin heavy chain $(\operatorname{IgH})$ and creatine transporter and cDNA related to myosin heavy chain (SLC6A8) paralogous pseudogenes, which map to proximal 16 . $^{21}{ }^{123}$ Normal chromosomes are thought to have two copies, and it is estimated that EV chromosomes have $12 .{ }^{123}$ Other components of this cassette have either been excluded (the $6 \mathrm{p}$ minisatellite ${ }^{123}$ ) or not yet tested for copy number variation at this locus (the adrenoleukodystrophy pseudogene $^{182}{ }^{183}$ ).

Variation in normal controls has also been found by Iafrate et al, ${ }^{184}$ who believe that the TP53TG3 (TP53 target gene 3 ) is included, and the $2.5 \mathrm{Mb}$ polymorphism (CNP 75) found by Sebat $e a^{178}$ in $16 \mathrm{pll}$ is likely to coincide with the $16 \mathrm{pll} 1.2$ EV.

\section{EVs and somatic variation}

One exceptional family, omitted from the Tables above, blurs the distinction between UBCAs and EVs. Savelyeva et al ${ }^{185}$ described three families with somatic inversions, duplications, and amplifications of a $\sim 2 \mathrm{Mb}$ segment of 9p23-p24 in association with BRCA2 insA mutations. In their family 3, the instability of $9 \mathrm{p}$ was found in a mutation carrying father as well as his phenotypically normal mutation negative son. In this case, it is as if the somatic instability associated with a gene mutation has been transmitted as an independent trait in the germ line. Limited unpublished observations in this laboratory suggest that copy number of the domain involved in the 8p23.1 EVs can also be amplified in somatic cells.

\section{DISCUSSION}

In this review, 200 families with microscopically visible cytogenetic anomalies have been separated into two groups of 130 families with UBCAs and 70 with EVs. These have then been subdivided into three groups depending on the presence or absence of phenotypic consequences in parents and children (table 3 ).

Among the UBCA families, most have a degree of phenotypic effect and thus, at the cytogenetic level, a lack of phenotypic consequences is the exception rather than the rule. However, discussion with colleagues suggests that UBCAs without phenotypic effect are frequently not published and therefore more common than is apparent from the literature. The data in this review are consistent with the idea that microscopic and submicroscopic imbalances of multiple evolutionarily conserved loci can be compatible with a normal phenotype. ${ }^{186}$

\section{Alternative explanations for the phenotypic variability in transmitted UBCAs Group 1}

1. Ascertainment bias: the majority of Group 1 imbalances were ascertained at prenatal diagnosis for maternal age and may therefore be skewed towards the mildly or unaffected end of the phenotypic spectrum. ${ }^{187}$ In addition, few of the children who were reportedly 
Table 3 Summary of the three groups

\begin{tabular}{|c|c|c|}
\hline \multirow[b]{2}{*}{ Groups } & \multicolumn{2}{|l|}{ Type of transmitted chromosome anomaly } \\
\hline & Transmitted UBCAs $(n=130)$ & Euchromatic variants (EVs) $(n=70)$ \\
\hline Groups 1 to 3 & $\begin{array}{l}\text { Copy number not variable in the normal population. } \\
\text { Chromosomal segments of several megabases in size; } \\
\text { copy number change usually plus or minus one. } \\
\text { Most have phenotypic consequences. }\end{array}$ & $\begin{array}{l}\text { Copy number variable in the normal population. Pseudogene or gene } \\
\text { casettes of limited extent; relatively high copy number changes needed } \\
\text { for cytogenetic visibility. None has established phenotypic } \\
\text { consequences. }\end{array}$ \\
\hline $\begin{array}{l}\text { Group 1: normal offspring } \\
\text { with normal parents }\end{array}$ & $\begin{array}{l}\mathrm{n}=23(18 \%) \text {. Most group } 1 \text { families ascertained at } \\
\text { prenatal diagnosis. Unknown whether post-natally } \\
\text { ascertained cases would also be free of phenotypic } \\
\text { effect. Homozygous imbalances of the same type } \\
\text { unlikely to be equally free of phenotypic consequences. }\end{array}$ & $\begin{array}{l}\mathrm{n}=38(54 \%) \text {. Most group } 1 \text { families ascertained at prenatal diagnosis. } \\
\text { Assumed that postnatally ascertained cases also free of phenotypic } \\
\text { effect. Homozygous copy number variants unlikely to have significant } \\
\text { phenotypic consequences. }\end{array}$ \\
\hline $\begin{array}{l}\text { Group 2: affected offspring } \\
\text { with normal parents }\end{array}$ & $\begin{array}{l}\mathrm{n}=30(23 \%) \text {. Most group } 2 \text { families ascertained } v \\
\text { ia phenotype of offspring. Some likely to be } \\
\text { coincidental to phenotype, some causal and some } \\
\text { of uncertain significance. }\end{array}$ & $\begin{array}{l}n=30(43 \%) \text {. Most group } 2 \text { families ascertained via phenotype of } \\
\text { offspring. Phenotype of probands assumed to reflect ascertainment } \\
\text { bias in all cases. }\end{array}$ \\
\hline $\begin{array}{l}\text { Group 3: affected offspring } \\
\text { with affected parents }\end{array}$ & $\begin{array}{l}\mathrm{n}=77(59 \%) \text {. Common co-segregation of group } 3 \\
\text { imbalance and mild phenotype common and likely to } \\
\text { be causal in the great majority of families. }\end{array}$ & $\begin{array}{l}n=2(3 \%) \text {. Rare co-segregation of group } 3 \text { variant and mild } \\
\text { phenotype regarded as coincidental in both families. }\end{array}$ \\
\hline
\end{tabular}

normal at term have been followed up over a period of years by a medical geneticist.

2. Low gene content especially in $G$ dark, late replicating euchromatin: many of the group 1 deletions involve $G$ dark bands to which few genes map. ${ }^{1}$ However, deletions and duplications that include $G$ light bands are also compatible with a normal phenotype (fig 1), and deletions restricted to a single $\mathrm{G}$ dark band may also have phenotypic consequences, for example, the 14q31 deletion associated with developmental delay and minor dysmorphism in at least three members of the Group 3 family reported by Byth et al. ${ }^{63}$

3. Absence of dosage sensitive loci: it is well known that many genes are not dosage sensitive, and imbalances involving a limited number of genes may not include genes that are dosage sensitive.

4. Functional redundancy: deletions or duplications of genes that have additional or related copies outside an imbalanced segment may have no detectable effect on the phenotype. $\mathrm{Gu}^{188}$ has reviewed whole genome analyses in yeast that suggest that alternative metabolic pathways can substitute for a pathway affected by mutation or that functional complementation can arise from duplicate genes. It has also been suggested that deletions involving gene clusters may be better buffered because of the remaining cluster of related genes on the normal homologue. ${ }^{1}$ A similar argument can be made for the deletion of genes that have related copies on other chromosomes. ${ }^{25}$

5. Allelic exclusion: Knight ${ }^{189}$ has reviewed the growing evidence that specific alleles have allele-specific levels of expression. It is conceivable that a high expressing allele could compensate for a deleted locus and a low expressing allele for a duplicated gene in a given individual but unlikely that these would be coinherited over several generations of the same family.

\section{Group 2}

1. Ascertainment bias: fertility may itself be a selector of more mildly affected individuals. In addition, phenotypically affected children or young adults are more likely to come to medical attention than their mildly affected or unaffected parents; in five families with transmitted microscopic and submicroscopic deletions of 22q11.2, congenital heart disease was more common in affected children than in affected parents, and some mildly affected siblings would have been unlikely to have been ascertained in the absence of their more severely affected brothers or sisters. ${ }^{175}$

2. Imprinting: this is an established mechanism for the discordant phenotypes associated with transmitted duplications of the TNDM locus (6q24.2) or the PWACR (15q11.2-q13) but an unlikely reason in regions that are not known to be imprinted.

3. Phenotypic variation extending into the normal range: in a number of UBCA families, a mildly affected proband has an unaffected parent with the same imbalance.

4. Chromosomal non-penetrance: if deletions and duplications involve only one or few dosage critical loci, then the non-penetrance associated with single locus Mendelian conditions may apply. In addition, the action of a modifier gene on a key dosage sensitive locus might result in the presence or absence of a phenotypic effect depending on the presence or absence of a modifying allele.

5. Unmasking of a recessive allele in a proband: this could result in effective nullisomy of a gene within a deletion. Alternatively, the lack of a second somatic mutation is likely to explain the lack of retinoblastoma in the mother of an affected child in the group 2 family with a deletion of $13 \mathrm{q} 14 .^{26}$

6. Mosaicism in a parent: most parental karyotypes were established from peripheral blood samples in two generation pedigrees and mosaicism has been established in some (see imbalances with an " $\mathrm{m}$ " in fig 1). Mosaicism is, however, an unlikely explanation in pedigrees where only the probands are affected and there are three or more generations with the same imbalance.

7. Undetected differences at the molecular level: most of these abnormalities are characterised at the cytogenetic level, and possible molecular differences have not been excluded.

8. Unreported abnormal phenotype: it is frequently assumed that parents are phenotypically normal although closer inspection by a clinical geneticist might reveal subtle anomalies that might otherwise escape detection, for example, deletions of distal $5 p$ were initially reported in developmentally delayed children and normal parents in the abstract by Bengtsson et al, ${ }^{190}$ but mild effects in parents were later described. ${ }^{54}$

9. Coincidence: any other unidentified genetic, epigenetic, or environmental factor that could coincide with a karyotypic abnormality that would otherwise be phenotypically neutral. 


\section{Group 3}

1. Consistently mild phenotype: survival into adulthood, fertility, and relatively independent lives are the hallmarks of families in group 3, among whom the majority have imbalances that consistently give rise to relatively mild phenotypic abnormalities.

2. Chance co-segregation: it may be necessary to examine the wider family to establish whether genotype and phenotype co-segregate by chance.

\section{Microscopic and submicroscopic UBCAs and EVs}

The fact that group 1 cytogenetic UBCAs ranging in size from $\sim 4$ to $\sim 30 \mathrm{Mb}$ can be free of phenotypic effect implies that a much higher proportion of subcytogenetic imbalances will also be compatible with fertility and a phenotype in the normal range. Using high resolution CGH with a resolution of $\sim 2 \mathrm{Mb}$, Kirchhoff et $\mathrm{al}^{145}{ }^{147}$ have already found that $\sim 10 \%$ of the identified imbalances are transmitted, although not all are associated with a normal phenotype. Testing for subtelomeric imbalances has identified transmitted imbalances with and without phenotypic effects, and "polymorphic" deletions and duplications that occur in more than one independent family..$^{146} 163164191192$ Using l Mb resolution array CGH on two different sets of patients, $\sim 50 \%$ of identified imbalances in a total of 70 patients were transmitted. ${ }^{148} 149$

Deletions, duplications, and copy number variation at the molecular level have been reviewed by Buckland, ${ }^{193}$ and $1 \mathrm{Mb}$ arrays are also providing evidence of large scale copy number variation. ${ }^{184}$ An idea of the level of polymorphism that will be found using tiling path arrays has been provided by Sebat et $a l,{ }^{178}$ who found 76 copy number differences of segments with an average size of $\sim 500 \mathrm{~kb}$ in 20 normal individuals using representational oligonucleotide microarray analysis. Some of the band assignments of these copy number variations (CNVs) coincide with some of the UBCAs in this review but, in general, it is unlikely that variation of a $500 \mathrm{~kb}$ CNV within a large confirmed UBCA has a significant impact on the presence or absence of any associated phenotype. The fact that the established EVs map to paralogous repeat regions hampers direct comparisons, although areas of likely overlap are indicated under the individual EV entries above and are being collected in the Database of Genomic Variants (http:// projects.tcag.ca/variation/). As the size of UBCAs and CNVs approaches each other, the distinction between a large single copy CNV and a short UBCA may become a matter of semantics.

The EVs identified to date clearly do not have the phenotypic consequences associated with UBCAs. However, their gene content and copy number variation in normal individuals does not exclude a possible role in traits that show continuous variation. It is also interesting that some of the human EVs involve genes that have testis specific expression (for example SPAG11 in the 8p23.1 EVs); additional copies of a variable domain might be under strong selection if they conferred a significant effect on fertility. A possible role for the 20000 pseudogenes in the human genome has also been raised by Hirotsune et al, ${ }^{194}$ who found that interruption of the makorin-1 pseudogene in transfection experiments had a detrimental affect on expression of the wild type makorin-1 gene. Copy number variation is also associated with the low copy repeats and duplicons that predispose to genomic disorders, ${ }^{195}{ }^{196}$ chromosome abnormalities, ${ }^{197} 198$ and evolutionary breakpoints. ${ }^{199}$ It therefore remains possible that the frequency and consequences of aberrant recombination between these repeats is influenced by copy number variation at homologous and paralogous sites.

\section{Transmission}

Table 1 indicates that there are more female than male transmitting carriers in the UBCA groups 1 and 2 in comparison with EV groups 1 and 2. This trend was more pronounced in the affected carriers of group 3. This suggests that unbalanced chromosome complements may have a more deleterious affect on male than female meiosis, as has previously been suggested for balanced translocation and ring chromosome carriers. ${ }^{155}{ }^{200}$ Alternatively, the figures may reflect social differences, whereby a phenotypically affected man is less likely to be able to find a partner while a phenotypically affected woman might be more susceptible to exploitation by normal men. However, further detailed pedigree analysis will be necessary to distinguish between these possibilities with adjustment for ascertainment bias and inclusion of only those families in which both parents have been karyotyped.

\section{Reproductive implications}

Relatively little is known about the behaviour of UBCAs at meiosis. The great majority of the simple deletions and duplications in the UBCA families has apparently been transmitted without giving rise to any additional imbalance at the cytogenetic level. The same cannot be said of imbalances derived from translocations or insertions; in these families, the phenotypically normal family members have frequently been ascertained via siblings with more extensive unbalanced segregants of the same rearrangements (see many of the $\mathrm{PA}^{*}$ families in Appendices 1 and 2). In addition, a clinically normal father with an insertional duplication of $9 p$ transmitted a deletion of chromosome 5 to a proband with cri du chat syndrome; this deletion would not have been predicted unless the insertion is more complex than it appears at the cytogenetic level. ${ }^{159}$

Miscarriages were recorded in two group 1 UBCA families, $^{29}$ and seem likely to be incidental for two reasons: (a) imbalances small enough to be compatible with a normal phenotype would be unlikely to give rise to fetal demise, and (b) the duplication or deletion loop formed at meiosis is unlikely to provide an opportunity for recombination that could conceivably result in the generation of larger imbalances.

Similarly, four group 1 EV families were ascertained for miscarriages but it is difficult to reconcile phenotypically silent euchromatic variation with miscarriage unless such variation predisposes to other larger imbalances of the same chromosome or to non-disjunction of the whole chromosome. This has not been established in any of the families reviewed here to date.

\section{Nosology}

Polymorphism is strictly used for variation that has a frequency of $1 \%$ or more in the population. It is therefore a suitable term for the common copy number variation that underlies cytogenetic EVs, but not for rare transmitted deletions or duplications; these might be considered dimorphic or heteromorphic but cannot accurately be described as polymorphic.

It is common practice to call a deletion or duplication a variant once other phenotypically normal family members with the same imbalance have been identified, and Jalal and Ketterling ${ }^{151}$ have proposed that all UBCAs and EVs without phenotypic effect should be described as euchromatic variants. However, describing euchromatic deletions and duplications as variants is to modify a genotypic description with a phenotypic one and to confuse single copy number changes with more extensive copy number variation. Because most UBCAs without phenotype have only been described in single families, the term "deletion or duplication without phenotypic effect" has been preferred, ${ }^{150}$ and "phenotypic 
deletion variant" or phenotypic duplication variant" might be preferable once a number of families and/or individuals with similar imbalances have been assembled. Given the extensive copy number variation associated with EVs, it is proposed that the term euchromatic variant is restricted to the expanded range of copy number variation that is visible at the cytogenetic level.

The term "transmitted" is preferred to "familial" as the latter is also used in families where balanced rearrangements have given rise to more than one chromosomally unbalanced individual but no direct transmission from an unbalanced individual has taken place.

The abbreviation "var" for variant was replaced with " $\mathrm{v}$ " in ISCN 1995. ${ }^{201}$ The band description followed by " $\mathrm{V}$ " (for example, $8 \mathrm{p} 23.1 \mathrm{v}$ ) has therefore been used for euchromatic variation within cytogenetic bands that has no apparent phenotypic effect.

\section{Aetiology of chromosomal phenotypes}

When deletions and duplications of most of the autosomal complement of Drosophila were produced by Lindsley et al, ${ }^{202}$ the authors found few regions that were haplolethal or triplolethal, and concluded that most of the deleterious effects of segmental aneuploidy are caused by the "additive effects of genes that slightly reduce viability and not by the individual effects of a few aneuploid lethal genes among a large array of dosage insensitive loci". Consistent with the results of Lindsley et al, ${ }^{202}$ Epstein ${ }^{203}{ }^{204}$ proposed an "additive" model in which the phenotype is the consequence of the additive effects of altered copy number of each gene within an unbalanced chromosome segment. As a result, imbalances of restricted size would include fewer genetic loci and be less likely to have detectable phenotypic consequences. By contrast, Shapiro and others have proposed an "interactive" model, ${ }^{205206}$ in which the phenotype is the result of the destabilisation of developmental processes resulting from the cumulative and synergistic effects of all the unbalanced loci within a segmental imbalance. Under this model, it could be argued that small imbalances are insufficient to destabilise developmental processes to the point at which a phenotypic effect is detectable. The difference may not be academic; if the phenotype results from a few dosage sensitive loci, then the prognostic implications of a given imbalance could be inferred from the dosage of these key loci. If, however, the phenotype depends on the synergistic interactions of many genes of small effect, the diagnostic implications may be much harder to predict. ${ }^{207}$ In practice, chromosomal syndromes are likely to reflect a combination of both $(a)$ the effects of a relatively small number of dosage sensitive loci of large effect, for example, those within the critical regions for syndromes such as cri du chat, in which small interstitial deletions, large terminal deletions, and unbalanced translocations all result in a recognisable facial gestalt; and $(b)$ the cumulative effect of relatively large numbers of loci of individually small effect, for example, those imbalances of the short arm of chromosome 5 that do not include the cri du chat critical region and are generally associated with a milder, more non-specific phenotype. A Down's syndrome critical region (DCR) has also been identified, but extensive phenotypic analysis of partial duplications of chromosome 21 indicates that genes both inside and outside the putative DCR contribute to the phenotype of full trisomy 21 Down's syndrome. $^{208}$ In addition, expression analysis shows that Down's syndrome alters the dosage of genes on chromosome 21 as well as genes on other chromosomes. ${ }^{209}$

\section{CONCLUSIONS}

Evidence summarised in this review indicates that most transmitted UBCAs have phenotypic effects but there are a growing number of exceptions. These show that autosomal deletions and duplications with an average size of almost $10 \mathrm{Mb}$ are compatible with fertility and a normal phenotype, especially in families selected on the basis of the direct transmission of an imbalance between two or more family members. However, it has yet to be established that a given imbalance will be consistently free of phenotypic consequences in multiple independent families or as de novo events. Consequently, (a) not all transmitted imbalances with an affected proband and a normal parent will be coincidental, and careful analysis of the extended family may be necessary; and $(b)$ some de novo imbalances may not be causal, and knowledge of the gene content will not always discriminate between causal and non-causal rearrangements.

The established EVs represent an extreme of variation that is already reflected in the multiple copy number variants being identified at the subcytogenetic level ${ }^{178}$ and may be particularly associated with regions of recent paralogous gene transposition. ${ }^{123}$ Consequently, (a) phenotypically neutral subcytogenetic EVs will be a common finding that will need to be distinguished from pathogenic alterations, and $(b)$ although EVs are not associated with the detrimental effects of most UBCAs, copy number variation may yet be found to have a bearing on quantitative traits such as response to drugs or infection.

Diagnostic genetic services still encounter families who have lived for many years under the mistaken impression that heterochromatic variation, identified in the early years of conventional cytogenetics, was responsible for the congenital abnormalities, malignancy, or reproductive loss in a proband or family. ${ }^{198}$ This review provides classic cytogenetic precedents for areas of the genome that may be free of pathogenic consequences. However, the continuum of severity associated with UBCAs and subcytogenetic imbalances will require clinical genetic precision to exclude subtle phenotypic manifestations in otherwise phenotypically normal individuals, and laboratory resources to distinguish clinically silent variation from pathogenic rearrangement. ${ }^{210}$ To this end, data from this review are available at (http:// www.ngrl.org.uk/Wessex/collection.html). New resources such as the European Chromosome Abnormality Register of Unbalanced Chromosome Abnormalities (ECARUCA) (http://www.ecaruca.net/), the DatabasE of Chromosomal Imbalance and Phenotype in Humans using Ensembl Resources (DECIPHER) (http://www.sanger.ac.uk/PostGenomics/decipher/) and the Database of Genomic Variants (http://projects.tcag.ca/variation/) will provide the means of accelerating the process of distinguishing pathogenic alterations from phenotypically neutral variation in the immediate future.

\section{ACKNOWLEDGEMENTS}

$\mathrm{P}$ Jacobs, A Sharp, and $\mathrm{N}$ Cross are thanked for their helpful comments on this review. VMaloney is thanked for constructing the idiograms and J Gladding for her help with the preparation of the manuscript.

\section{Author's affiliations \\ J C K Barber, Wessex Regional Genetics Laboratory, Salisbury Health Care NHS Trust, Salisbury District Hospital, Salisbury, Wiltshire SP2 8BJ, UK; Human Genetics Division, Duthie Building, Southampton University Hospitals Trust, Tremona Road, Southampton, UK; National Genetics Reference Laboratory (Wessex), Salisbury Health Care NHS Trust, Salisbury District Hospital, Salisbury, Wiltshire SP2 8BJ, UK \\ Competing interests: none declared}




\section{REFERENCES}

1 Barber JCK, Thomas NS, Collinson MN, Dennis NR, Liehr T, Weise A Belitz B, Pfeiffer L, Kirchhoff M, Krag-Olsen B, Lundsteen C. Segmenta haplosufficiency; transmitted deletions of $2 \mathrm{p} 12$ include a pancreatic regeneration gene cluster and have no apparent phenotypic consequences. Eur J Hum Genet 2005;13:283-91.

2 Sumption ND, Barber JCK. Transmitted deletion of $2 q 13$ to $2 q 14.1$ causes no phenotypic abnormalities. J Med Genet 2001;38:125-6

3 Knight LA, Yong MH, Tan M, Ng ISL. Del(3)(p25.3) without phenotypic effect. J Med Genet 1993;30:613.

4 Overhauser J, Golbus MS, Schonberg SA, Wasmuth JJ. Molecular analysis of an unbalanced deletion of the short arm of chromosome 5 that produces no phenotype. Am J Hum Genet 1986;39:1-10.

5 Reddy KS. A paternally inherited terminal deletion, del(8)(p23.1)pat, detected prenatally in an amniotic fluid sample: a review of deletion 8p23.1 cases. Prenat Diagn 1999;19:868-72.

6 Batanian JR, Morris K, Ma E, Huang Y, McComb J. Familial deletion of (8)(q24.13q24.22) associated with a normal phenotype. Clin Genet 2001;60:371-3.

7 Pelly D, Barnes I. Deletion of $9 p$ in three generations without apparent phenotypic effect. J Med Genet 1992;29:210.

8 Barber JCK, Mahl H, Portch J, Crawfurd MD'A. Interstitial deletions without phenotypic effect: prenatal diagnosis of a new family and brief review. Prenat Diagn 1991:11:411-16.

9 Couturier J, Morichon-Delvallez N, Dutrillaux B. Deletion of band 13q21 is compatible with normal phenotype. Hum Genet 1985;70:87-91

10 Hand JL, Michels VV, Marinello MJ, Ketterling RP, Jalal SM. Inherited interstitial deletion of chromosomes $5 \mathrm{p}$ and $16 \mathrm{q}$ without apparent phenotypic effect: further confirmation. Prenat Diagn 2000;20:144-8.

11 Witt DR, Lew SP, Mann J. Heritable deletion of band 16q21 with normal phenotype: relationship to late replicating DNA. Am J Hum Genet 1988;43(suppl):A127.

12 Millard M, Roman D, Weber C, Wobser J, Moore J. Chromosome abnormalities and variants with no apparent clinical significance. J Assoc Genet Technol 1998;24:A151

13 Zaslav AL, Blumenthal D, Fox JE, Thomson KA, Segraves R, Weinstein ME. A rare inherited euchromatic heteromorphism on chromosome 1. Prenat Diag 1993;13:569-73.

14 Engelen JJM, Moog U, Evers JLH, Dassen H, Albrechts JCM, Hamers AJH Duplication of 8p23.1 $\rightarrow$ p23.2: A Benign Variant.? Am J Med Genet 2000;91:18-21.

15 Chan S, Dill FJ, Langlois S, Pantzar JT, Lomax B, Rajcan-Separovic E. Segregation of a novel euchromatic expansion of $8 p 22$ in three generations with no associated phenotypic abnormalities. Am J Hum Genet 2003;73(suppl):316.

16 Saxe D, Coleman L, Miley D, Yearall A, Sanders T, May K. Familial case of duplication 10p without phenotypic effect. Am J Hum Genet 2003;7(suppl):308

17 Liehr T, Schreyer I, Neumann A, Beensen V, Ziegler M, Hartmann I, Starke H Heller A, Nietzel A, Claussen U. Two more possible piffalls of rapid prenata diagnostics using interphase nuclei. Prenat Diagn 2002;22:497-9.

18 Wolff DJ, Raffel U, Ferre MM, Schwartz S. Prenatal ascertainment of an inherited dup (18p) associated with an apparently normal phenotype. Am J Med Genet 1991;41:319-21.

19 Carr DM, Moore H, Beurkdzhyan T. Unbalanced chromosome number one in normal progeny and carrier father. Am J Hum Genet 1988;43(suppl):A104.

20 Borgaonkar DS, Bias WB, Chase GA, Sadasivan G, Herr HM, Golomb HM Bahr GF. Identification of a C6/G21 translocation chromosome by the Q-M and Giemsa banding techniques in a patient with Down's syndrome, with possible assignment of Gm locus. Clin Genet 1973;4:53-7.

21 Barber JCK. An investigation of euchromatic cytogenetic imbalances without phenotypic effect. PhD Thesis. Southampton: University of Southampton, 2000.

22 Gersh M, Goodart SA, Pasztor LM, Harris DJ, Weiss L, Overhauser J. Evidence for a distinct region causing a cat-like cry in patients with $5 p$ deletions. Am J Hum Genet 1995;56:1404-10.

23 Johnson El, Marinescu RC, Punnett HH, Tenenholz B, Overhauser J. 5p14 deletion associated with microcephaly and seizures. J Med Genet 2000;37:125-7.

24 Mascarello JT, Hubbard V. Routine use of methods for improved G-band resolution in a population of patients with malformations and developmental delay. Am J Med Genet 1991;38:37-42.

25 Li L, Moore P, Ngo C, Petrovic V, White SM, Northrop E, loannou PA McKinlay Gardner RJ', Slater HR. Identification of a haplosufficient 3.6-Mb region in human chromosome 11 q14.3->q21. Cytogenet Genome Res 2002:97:158-62.

26 Cowell JK, Rutland R, Hungerford J, Jay M. Deletion of chromosome region $13 q 14$ is transmissible and does not always predispose to retinoblastoma. Hum Genet 1988;80:43-5.

27 Chan NP, Ng MH, Cheng SH, Lee V, Tsang KS, Lau TT, Li CK. Hereditary duplication of proximal chromosome lq (q1 lq22) in a patient with $\mathrm{T}$ lymphoblastic lymphoma/leukaemia: a family study using $G$ banding and comparative genomic hybridisation. J Med Genet 2002;39:e79.

28 Bortotto L, Piovan E, Furlan R, Rivera H, Zuffardi O. Chromosome imbalance, normal phenotype, and imprinting. J Med Genet 1990;27:582-7.

29 Fryburg JS, Shashi V, Kelly TE. Genomic imprinting as a probable explanation for variable intrafamilial phenotypic expression of an unusual chromosome 3 abnormality. Am J Hum Genet 1994;55(suppl):A104.
30 Maltby EL, Barnes ICS, Bennett CP. Duplication involving band $4 q 32$ with minimal clinical effect. Am J Med Genet 1999;83:431

31 Li S-Y, Gibson LH, Gomez K, Pober BR, Yang-Feng TL. Familial dup (5)(q15q21) associated with normal and abnormal phenotypes. Am J Med Genet 1998:75:75-7.

32 Harada N, Takano J, Kondoh T, Ohashi H, Hasegawa T, Sugawara H, Ida T, Yoshiura K, Ohta T, Kishino T, Kajii T, Niikawa N, Matsumoto N. Duplication of 8p23.2: a benign cytogenetic variant? Am J Med Genet 2002;111:285-8.

33 Tsai C-H, Graw SL, McGavran L. 8p23 duplication reconsidered: is it a true euchromatic variant with no clinical manifestation? J Med Genet 2002;39:769-74.

34 Robin NH, Harari-Shacham A, Schwartz S, Wolff D. Duplication $14(\mathrm{q} 24.3 \mathrm{q} 31$ ) in a father and daughter: delineation of a possible imprinted region. Am J Med Genet 1997;71:361-365.

35 Bolton PF, Dennis NR, Browne CE, Thomas NS, Veltman MW, Thompson RJ, Jacobs P. The phenotypic manifestations of interstitial duplications of proximal $15 \mathrm{q}$ with special reference to the autistic spectrum disorders. Am J Med Genet 2001;105:675-85.

36 Hirsch B, Heggie P, McConnell K. Inherited direct duplication of 15q11$15 q 12$ including loci D15S1 1-GABRB3 in a child with autism. Am J Hum Genet 1995;57(suppl):A1 16.

37 Cook EH Jr, Lindgren V, Leventhal BL, Courchesne R, Lincoln A, Shulman C, Lord C. Autism or atypical autism in maternally but not paternally derived proximal 15q duplication. Am J Hum Genet 1997;60:928-934.

38 Gurrieri F, Battaglia A, Torrisi L, Tancredi R, Cavallaro C, Sangiorgi E, Neri G. Pervasive developmental disorder and epilepsy due to maternally derived duplication of 15q11-q13. Neurology 1999;52:1694-7.

39 Schroer RJ, Phelan MC, Michaelis RC, Crawford EC, Skinner SA, Cuccaro M, Simensen RJ, Bishop J, Skinner C, Fender D, Stevenson RE. Autism and maternally derived aberrations of chromosome 15q. Am J Med Genet 1998;76:327-36.

40 Verma RS, Kleyman SM, Conte RA. Variant euchromatic band within 16q12.1. Clin Genet 1997;52:446-7.

41 Temple IK, Gardner RJ, Robinson DO, Kibirige MS, Fergusson AW, Baum JD, Barber JCK, James RS, Shielf JPH. Further evidence for an imprinted gene for neonatal diabetes localised to chromosome 6q22-q23. Hum Mol Genet 1996:5:1117-23.

42 Guichaova MR, Speed RM, Luciani JM, Delafontaine D, Chandley AC Infertility in human males with autosomal translocations .2. Meiotic studies in 3 reciprocal rearrangements, one showing tertiary monosomy in a 45 chromosome individual and his father. Cytogenet Cell Genet 1992;60:96-101.

43 Fu W, Borgaonkar DS, Ladewig PP, Weaver J, Pomerance HH. Structural aberrations of the long arm of chromosome no.22. Clin Genet 1976;10:329-36.

44 Pfeiffer RA, Kessel EK, Soer K-H. Partial trisomies of chromosome 21 in man Two new observations due to translocations 19;21 and 4;21. Clin Genet 1977;11:207-13.

45 Sanford Hanna JA, Ball S, Pagon RA, Donlan M. Mother to son transmission of del(1) (q42.1q42.3). Am J Med Genet 2001;98:103-6.

46 Tazelaar J, Roberson J, Vandyke DL, Babu VR, Weiss L. Mother and son with deletion of 3p25-pter. Am J Med Genet 1991;39:130-2.

47 Tonk VS, Jalal SM, Gonzalez J, Kennedy A, Velagaleti GV. Familial interstitial deletion of chromosome 4 (p15.2p16.1). Ann Genet 2003;46:453-8.

48 Herzog R, Babu A, Popescu S, Konstantinovska F, Punales-Morejon D, Kupchik G, Penchaszadeh VB. Chromosome 4 deletion ( $4 q 33-4 q$ ter) in a mother and son. Am J Hum Genet 1993;53:19.

49 Curtis MA, Smith RA, Sibert J, Hughes HE. Interstitial deletion, del(4) (q33q35.1) in a mother and two children. J Med Genef 1989;26:652-4.

50 Gould CP, Miller PR, Larkins SA, McKee S, Morton J, Adhami A, Davison EV. Inherited deletions of chromosome 4, del(4)(q32q33) and del(4)(q33q33) in two unrelated families. ACC Spring Conf 1999:18:21

51 Baccichetti C, Lenzini E, Artifoni L, Caufin D, Marangoni P. Terminal deletion of the short arm of chromosome 5. Clin Genet 1988;34:219-23.

52 Hill SM, Waters JJ, Mercer AM, McKeown CME, Hulten MA. A 5p deletion in a 2 generation family: cytogenetic and FISH studies. Clin Cytog Bull 1990;2:37.

53 Cornish KM, Cross G, Green A, Willatt L, Bradshaw JM. A neuropsychological-genetic profile of atypical cri du chat syndrome implications for prognosis. J Med Genet 1999;36:567-70.

54 Church DM, Bengtsson U, Nielsen KV, Wasmuth JJ, Niebuhr E. Molecular definition of deletions of different segments of distal $5 p$ that result in distinct phenotypic features. Am J Hum Genet 1995;56:1162-72.

55 Kushnick T, Rao KW, Lamb AN. Familial 5p-syndrome. Clin Genet 1984;26:472-6.

56 Martinez JE, Tuck-Muller CM, Superneau D, Wertelecki W. Fertility and the cri du chat syndrome. Clin Genet 1993;43:212-14.

57 Keppen LD, Gollin SM, Edwards D, Sawyer J, Wilson W, Overhauser J. Clinical phenotype and molecular analysis of a three-generation family with an interstitial deletion of the short arm of chromosome 5. Am J Med Genet 1992:44:356-60.

58 Walker JL, Blank CE, Smith BA. Interstitial deletion of the short arm of chromosome 5 in a mother and three children. J Med Genet 1984;21:465-7.

59 Pettenati MJ, Rao N, Johnson C, Hayworth R, Crandall K, Huff O, Thomas IT. Molecular cytogenetic analysis of a familial 8p23.1 deletion associated with minimal dysmorphic features, seizures, and mild mental retardation. Hum Genet 1992;89:602-6. 
60 Magenis RE, Lahr M, Hefits-Borchardt VA, Lawce $\mathrm{H}$, Wilson T. Inherited microdeletion syndrome, due to loss of single band 9q31.3: the continuing case for high resolution chromosome studies in unexplained mild mental retardation. Am J Hum Genet 1989;45(suppl):A81 .

61 Neavel CB, Soukup S. Deletion of (1 1)(q24.2) in a mother and daughter with similar phenotypes. Am J Med Genet 1994;53:321-324

62 Fukushima Y, Kuroki Y, Ito T, Kondo I, Nishigaki I. Familial retinoblastoma (mother and son) with 13q14 deletion. Hum Genet 1987;77:104-7.

63 Byth BC, Costa MT, Teshima IE, Wilson WG, Carter NP, Cox DW. Molecular analysis of three patients with interstitial deletions of chromosome band 14q31. J Med Genet 1995;32:564-57.

64 Michaelis RC, Skinner SA, Lethco BA, Simensen RJ, Donlon TA, Tarleton J, Phelan MC. Deletion involving D15S113 in a mother and son without Angelman syndrome: refinement of the Angelman syndrome critical deletion region. Am J Med Genet 1995;55:120-6.

65 Rigola MA, Plaja A, Mediano C, Miro R, Egozcue J, Fuster C. Characterization of a heritable partial monosomy $18 p$ by molecular and cytogenetic analysis. Am J Med Genet 2001;104:37-41.

66 Say B, Gopal Rao VVN, Harris S, Coldwell J, Carpenter NJ, Chapman HA. Familial deletion of 18p associated with Turner like clinical features. Am J Hum Genet 1994;55(suppl):A1 17.

67 Tonk V, Krishna J. Case report: denovo inherited 18p deletion in a motherfetus pair with extremely variable expression, confirmed by fluorescence in situ hybridization (FISH) analysis. Eur J Obstet Gynecol Reprod Biol 1997;73:193-6.

68 Tsukahara M, Imaizumi K, Fujita K, Tateishi H, Uchida M. Familial Del(18p) syndrome. Am J Med Genet 2001;99:67-9.

69 Velagaleti GVN, Harris S, Carpenter NJ, Coldwell J, Say B. Familial deletion of chromosome 18 (p1 1.2). Ann Genet Paris 1996;39:201-4.

70 Uchida IA, McRae KN, Wang HC, Ray M. Familial short arm deficiency of chromosome 18 concomitant with arhinencephaly and alopecia congenita. Am J Hum Genet 1965;17:411-19.

71 Strathdee G, Sutherland R, Jonsson JJ, Sataloff R, Kohonen-Corish M, Grady D, Overhauser J. Molecular characterisation of patients with 18q23 deletions. Am J Hum Genet 1997:60:860-8.

72 Subrt I, Pokorny J. Familial ocurrence of 18q-. Hum Genet 1970;10:181-7.

73 Miller G, Mowrey PN, Hopper KD, Frankel CA, Ladda RL. Neurologic manifestations in 18q- syndrome. Am J Med Genet 1990:37:128-32.

74 Anad F, Burn J, Matthews D, Cross I, Davison BCC, Mueller R, Sands M Lillington DM, Eastham E. Alagille syndrome and deletion of 20p. J Med Genet 1990;27:729-737

75 Roland B, Chernos JE, Cox DM. 9qh variant band in two families. Am J Med Genet 1992;42:137-8.

76 Wilson DI, Cross IE, Goodship JA, Coulthard S, Carey AH, Scambler PJ Bain HH, Hunter AS, Carter PE, Burn J. DiGeorge syndrome with isolated aortic coarctation and isolated ventricular septal defect in three sibs with a 22q1 1 deletion of maternal origin. Br Heart J 1991;66:308-12.

77 Van Dyke DL. Isochromosomes and interstitial tandem direct and inverted duplications. In: Liss AR, ed. The cytogenetics of mammalian autosomal rearrangements. New York: Alan R Liss, 1988:635-65.

78 Wilson D, Cox H, Fiegler H, Wilkinson K, Fowler D, Moore K, Carter NP, Wellesley D, Barber J. Congenital heart disease, deafness and duplications of 3q; refining a new syndrome. J Med Genet 2003;40(suppl 1):S60.

79 Goodman BK, Capone GT, Hennessey J, Thomas GH. Familial tandem duplication of bands q31.1 to q32.3 on chromosome 4 with mild phenotypic effect. Am J Med Genet 1997;73:1 19-24.

80 Stallard R, Zurcher V, Schwartz S. Duplication of $5 q 21$ in a mildly retarded male and his non-retarded mother. Am J Hum Genet 1994;55(suppl):A1 18

81 Schaefer GB, Novak K, Steele D, Buehler B, Smith S, Zaleski D, Pickering D, Nelson M, Sander W. Familial inverted duplication 7p. Am J Med Genet 1995; 56:184-7.

82 Joyce CA, Sharp A, Walker JM, Bullman H, Temple IK. Duplication of 7p12.1-p13, including GRB10 and IGFBP1, in a mother and daughter with features of Russell-Silver syndrome. Hum Genet 1999;105:273-80.

83 Kulharya AS, Norris KN, Sekul EA. Does anticipation exist for some familial chromosome abnormalities? Am J Hum Genet 1999;65(suppl):A168.

84 Kennedy SJ, Teebi AS, Adatia I, Teshima I. Inherited duplication, dup(8)(p23.1 p23.1) pat, in a father and daughter with congenital heart defects. Am J Med Genet 2001;104:79-80.

85 Engelen JJM, de Die-Smulders CEM, Sijstermans JMJ, Meers LEC Albrechts JCM, Hamers AJH. Familial partial trisomy $8 p$ without dysmorphic features and only mild mental retardation. J Med Genet 1995;32:792-5.

86 Fan YS, Siu VM, Jung JH, Farrell SA, Cote GB. Direct duplication of $8 \mathrm{p} 21.3 \rightarrow$ p23.1: a cytogenetic anomaly associated with developmental delay without consistent clinical features. Am J Med Genet 2001;103:231-4

87 Dhooge C, Vanroy N, Craen M, Speleman F. Direct transmission of a tandem duplication in the short arm of chromosome 8. Clin Genet 1994;5:36-9.

88 Moog U, Engelen JJ, Albrechts JC, Baars LG, de Die-Smulders CE. Familial dup(8)(p12p21.1): mild phenotypic effect and review of partial $8 p$ duplications. Am J Med Genet 2000;94:306-10.

89 Haddad BR, Lin AE, Wyandt H, Milunsky A. Molecular cytogenetic characterisation of the first familial case of partial 9p duplication (p22p24). J Med Genet 1996;33:1045-7.

90 Voullaire L, Gardner RJM, Vaux C, Robertson A, Oertel R, Slater H. Chromosomal duplication of band 10pl 4 segregating through four generations. J Med Genet 2000;37:233-7.

91 Witt DR, Jenkins L, Pinheiro S, Bros L, Jones C. Inherited partial direct duplication of $11 \mathrm{q}$. First report and possible association with a midline developmental field defect. Am J Hum Genet 1994;55(suppl):A122.
92 Pot MLH Giltay JC, van Wilsen A, Breslau-Siderius EJ. Unbalanced karyotype, dup 14(q13-q22), in a mother and her two children. Clin Genet 1996;50:398-402.

93 Thomas JA, Johnson J, Peterson Kraai TL, Wilson R, Tartaglia N, LeRoux J, Beischel L, McGavran L, Hagerman RJ. Genetic and clinical characterization of patients with an interstitial duplication $15 q 11-q 13$, emphasizing behavioral phenotype and response to treatment. Am J Med Genet 2003;119A: $111-20$

94 Barber JCK, Ziang S, Friend N, Collins AL, Hastings R, Farren B, Barnicoat A, Ye S. Transmitted duplications of proximal $16 \mathrm{q}$ flanked by heterochromatin; two new families with no evidence of a position effect. Hum Genet submitted.

95 Moog U, Engelen JJM, de Die-Smulders CEM, Albrechts JCM, Loneus WH, Haagen AAM, Raven EJM, Hamers AJH. Partial trisomy of the short arm of chromosome 18 due to inversion duplication and direct duplication. Clin Genet 1994;46:423-9.

96 Glass IA, Stormer P, Oei PTSP, Hacking E, Cotter PD. Trisomy 2q1 1.2-q21 1 resulting from an unbalanced insertion in two generations. J Med Genet 1998;35:319-22.

97 Slavotinek A, Maher E, Gregory P, Rowlandson P, Huson SM. The phenotypic effects of chromosome rearrangement involving bands $7 q 21.3$ and 22q13.3. J Med Genet 1997;34:857-61.

98 Stone D, Ning Y, Guan XY, Kaiser-Kupfer M, Wynshaw-Boris A, Biesecker L. Characterization of familial partial 10p trisomy by chromosomal microdissection, FISH, and microsatellite dosage analysis. Hum Genet 1996;98:396-402.

99 Bezrookove V, Hansson K, van der Burg M, van der Smagt JJ, HilhorstHofstee Y, Wiegant J, Beverstock GC, Raap AK, Tanke H, Breuning MH Rosenberg C. Individuals with abnormal phenotype and normal G-banding karyotype: improvement and limitations in the diagnosis by the use of 24colour FISH. Hum Genet 2000;106:392-8.

100 Cooke A, Tolmie JL, Colgan JM, Greig CM, Connor JM. Detection of an unbalanced translocation $(4 ; 14)$ in a mildly retarded father and son by flow cytometry. Hum Genet 1989;83:83-7.

101 Greenberg F, Crowder WE, Paschall V, Colon-Linares J, Lubianski B, Ledbetter DH. Familial DiGeorge syndrome and associated partial monosomy of chromosome 22. Hum Genet 1984;65:317-19.

102 Luthardt FW, Shadoan PK, Mains AE, Keitges EA, Hudgins LH, Church DM, Skogerboe KJ, Bengtsson U, Wasmuth JJ. Cytogenetic, molecular and clinical evaluation of an unbalanced familial 5p15.3 abnormality transmitted through four-generations. Am J Hum Genet 1995:97(suppl):A1 19.

103 Barber JCK, Temple IK, Campbell PL, Collinson MN, Campbell CM Renshaw RM, Dennis NR. Unbalanced translocation in a mother and her son in one of two 5;10 translocation families. Am J Med Genet 1996:62:84-91.

104 Aviv H, Lieber C, Yenamandra A, Desposito F. Familial transmission of a deletion of chromosome 21 derived from a translocation between chromosome 21 and an inverted chromosome 22. Am J Med Genet 1997;70:399-404.

105 Delatycki MB, Voullaire L, Francis D, Petrovic V, Robertson A, Webber LM, Slater HR. Directly inherited partial trisomy of chromosome 6p identified in a father and daughter by chromosome microdissection. J Med Genet 1999;36:335-8

106 Brooks SS, Genovese M, Gu H, Duncan CJ, Shanske A, Jenkins EC. Normal adaptive function with learning disability in duplication 8p including p22. Am J Med Genet 1998;78:114-17.

107 O'Malley DP, Storto PD. Confirmation of the chromosome 8p23.1 euchromatic duplication as a variant with no clinical manifestations. Prenat Diagn 1999; 19:178-85.

108 Barber JCK, Joyce CA, Collinson MN, Nicholson JC, Willatt LR, Dyson HM, Bateman MS, Green AJ, Yates JRW, Dennis NR. Duplication of 8p23.1: a cytogenetic anomaly with no established clinical significance. J Med Genet 1998a;35:491-6.

109 Hollox EJ, Armour JA, Barber JC. Extensive normal copy number variation of a beta-defensin antimicrobial-gene cluster. Am J Hum Genet 2003;73:591-600

110 Williams L, Larkins S, Roberts E, Davison EV. Two further cases of variation in band 8p23.1. Not always a benign variant? J Med Genet 1996;33(suppl 1):A3.020.

111 Krasikov N, Lamb AN, Vetrano LA, Hansen JL, Menges DE, Lytle CH, Roherty SL, Davenport MB, Pauker S, Dolkart L, Davis G. Benign variant 8p23.1? Am J Hum Genet 1993;53(suppl):A568.

112 Webb G, Krumins E, Eichenbaum S, Voullaire L, Earl E, Choo K. Non Cbanding variants in some normal families might be homogeneously staining regions. Hum Genet 1989;82:59-62.

113 Buckton KE, O'Riordan ML, Ratcliffe S, Slight J, Mitchell M, McBeath S. A G-band study of chromosomes in liveborn infants. Ann Hum Genet 1980;43:227-39.

114 Archidiacono N, Pecile V, Rocchi M, Dalpra L, Nocera G, Simoni G. A rare non-heterochromatic $9 p+$ variant in two amniotic fluid cell cultures. Prenat Diagn 1984;4:231-3.

115 Wojiski SA, Harker Rhodes C, Brodhurst CA, Mohandas TK, Park JP. The G positive band of the rare euchromatic 9qh variant is derived from 9p 12. App Cyto 1997;23:125-8.

116 Docherty Z, Hulten MA. Rare variant of chromosome 9. Am J Med Genet 1993;45:105-6

117 Knight LA, Soon MG, Tan M. Extra positive band on the long arm of chromosome 9. J Med Genet 1995;32:994-5.

118 Roland B, Cox DM, Hoar DI, Fowlow SB, Robertson AS. A familial interstitial deletion of the long arm of chromosome 21. Clin Genet 1990;37:423-8.

119 Docherty Z, Hulten MA. Extra euchromatic band in the qh region of chromosome 9. J Med Genet 1985;22:157. 
120 Fantes JA, Mewborn SK, Lese CM, Hedrick J, Brown RL, Dyomin V, Chaganti RS, Christian SL, Ledbetter DH. Organisation of the pericentromeric region of chromosome 15: at least four partial gene copies are amplified in patients with a proximal duplication of 15q. J Med Genet 2002:39:170-7.

121 Browne CE, Dennis NR, Maher E, Long SL, Nicholson J, Sillibourne J, Barber JCK. Inherited interstitial duplications of proximal 15q: genotypephenotype correlations. Am J Hum Genet 1997:61:1342-52.

122 Jalal SM, Persons DL, Dewald GW, Lindor NM. Form of $15 q$ proximal duplication appears to be a normal euchromatic variant. Am J Med Genet 1994;52:495-7.

123 Barber JCK, Reed CJ, Dahoun SP, Joyce CA. Amplification of a pseudogene cassette underlies euchromatic variation of $16 p$ at the cytogenetic level. Hum Genet 1999;104:211-18.

124 Bogart MH, Bradshaw C, Jones OW. Prenatal diagnosis of euchromatic $16 \mathrm{p}+$ heteromorphisms in two unrelated families. Prenat Diagn 1991;11:417-18.

125 Croci G, Camurri L, Franchi F. A familial case of chromosome-16p variant J Med Genet 1991;28:60-4.

126 Thompson PW, Roberts SH, Rees SM. Replication studies in the 16p+ variant. Hum Genet 1990;84:371-2.

127 Bryke CR, Breg WR, Potluri VR, Yang-Feng TL. Duplication of euchromatin without phenotypic effects: a variant of chromosome 16. Am J Med Genet 1990;36:43-4.

128 Thompson PW, Roberts SH. A new variant of chromosome 16. Hum Genet 1987:76:100-1.

129 Begleiter ML, Cooper HA, Paszfor LM, Butler MG. Chromosome 8p23.1 duplication: is there an association with a clinical phenotype. Am J Hum Genet 2000;65(suppl):A158.

130 Sutherland GR, Eyre $H$. Two unusual G-bands variants of the short arm of chromosome 9. Clin Genet 1981;19:331-4.

131 Spedicato FS, Di Comite A, Tohidast-Akrad M. An unusual variant chromosome 9 with an extra C-negative, G-dark segment in the short arm. Clin Genet 1985;28:162-5.

132 Jalal SM, Kukolich MK, Garcia M, Day DW. Euchromatic 9q+ heteromorphism in a family. Am J Med Genet 1990a;37:155-6.

133 Barber JCK, Cross IE, Douglas F, Nicholson JC, Moore KJ, Browne CE. Neurofibromatosis pseudogene amplification underlies euchromatic cytogenetic duplications and triplications of proximal 15q. Hum Genet 1998b; 103:600-8.

134 Ludowese CJ, Thompson KJ, Sekhon GS, Pauli RM. Absence of predictable phenotypic expression in proximal 15q duplications. Clin Genet 1991:40:194-201.

135 Hoo J-J, Chao MC, Samuel IP, Morgan AM. Proximal 15q variant as possible piffall in the cytogenetic diagnosis of Prader-Willi syndrome. Clin Genet 1990;37:161-6.

136 Shohat M, Shohat T, Rimoin DL, Mohandas T, Heckenlively J, Magenis RE, Davidson MB, Korenberg JR. Rearrangement of Chromosome 15 in the region $\mathrm{q} 11.2 \rightarrow \mathrm{q} 12$ in an individual with obesity syndrome and her normal mother. Am J Med Genet 1990;37:173-7.

137 Brookwell R, Veleba A. Proximal $15 q$ variant with normal phenotype in three unrelated individuals. Clin Genet 1987:31:311-14.

138 Berry R, Mcgavran L, Robinson J, Staley L. Familial duplication of proximal $15 \mathrm{q}$ in Prader-Willi individual and her normal father. Am J Hum Genet 1987;41(suppl):A114.

139 Clark RE, Geddes D, Whittaker K, Jacobs A. Myelodysplastic syndrome in a kindred with ins(16)(p1 1.2). Clin Genet 1988;33:418-23.

140 Jalal SM, Schneider NR, Kukolich MK, Wilson GN. Euchromatic 16p+ heteromorphism: first report in North America. Am J Med Genet 1990b;37:548-50.

141 Hasegawa T, Asamura S, Nagai T, Tsuchiya Y. An unusual variant of chromosome 16 in three generations. Acta Paediatr Jpn 1992;34:166-8.

142 Gibbons B, Tan SY, Barber JCK, Ng CF, Knight LA, Lam S, Ng I. Duplication of $8 p$ with minimal phenotypic effect transmitted from a mother to her two daughters. J Med Genet 1999:36:419-22.

143 Mignon C, Parente F, Stavropoulou C, Collignon P, Moncla A, Turc-Carel C, Mattei $M-G$. Inherited DNA amplification of the proximal $15 q$ region: cytogenetic and molecular studies. J Med Genet 1997;34:217-22.

144 Stallard R, Van Dyke D. Familial duplications of proximal $15 q$ in normal individuals. Am J Hum Genet 1986;39(suppl):A133.

145 Kirchhoff M, Rose H, Lundsteen C. High resolution comparative genomic hybridisation in clinical cytogenetics. J Med Genet 2001;38:740-4.

146 Martin CL, Waggoner DJ, Wong A, Uhrig S, Roseberry JA, Hedrick JF, Pack SD, Russell K, Zackai E, Dobyns WB, Ledbetter DH. "Molecular rulers" for calibrating phenotypic effects of telomere imbalance. J Med Genet 2002;39:734-40.

147 Kirchhoff M, Pedersen S, Kjeldsen E, Rose H, Duno M, Kolvraa S, Lundsteen $\mathrm{C}$. Prospective study comparing HR-CGH and subtelomeric FISH for investigation of individuals with mental retardation and dysmorphic features and an update of a study using only HR-CGH. Am J Med Genet 2004; 127A: $111-17$

148 Vissers LE, de Vries BB, Osoegawa K, Janssen IM, Feuth T, Choy CO Straatman $\mathrm{H}$, van der Vliet W, Huys EH, van Rijk A, Smeets D, van Ravenswaaij-Arts CM, Knoers NV, van der Burgt I, de Jong PJ, Brunner HG, van Kessel AG, Schoenmakers EF, Veltman JA. Array-based comparative genomic hybridization for the genomewide detection of submicroscopic chromosomal abnormalities. Am J Hum Genet 2003:73:1261-70.

149 Shaw-Smith C, Redon R, Rickman L, Rio M, Willatt L, Fiegler H, Firth H, Sanlaville D, Winter R, Colleaux L, Bobrow M, Carter NP. Microarray based comparative genomic hybridisation (array-CGH) detects submicroscopic chromosomal deletions and duplications in patients with learning disability/ mental retardation and dysmorphic features. J Med Genet 2004;41:241-8.

150 Gardner RJM, Sutherland GR. Chromosome abnormalities and genetic counselling, 3rd edn. Oxford: Oxford University Press, 2004

151 In: Wyandt HE, Tonk VS, eds. Atlas of human chromosome heteromorphisms. Dordrecht: Kluwer Academic Publishers, 2004.

152 Faivre L, Morishon-Delvallez N, Viot G, Martinovic J, Pinson MP, Aubry JP, Raclin V, Edery P, Dumez Y, Munnich A, Vekemans M. Prenatal detection of a 1 p36 deletion in a fetus with multiple malformations and a review of the literature. Prenat Diagn 1999; 19:49-53.

153 Crolla JA. FISH and molecular studies of autosomal supernumerary marker chromosomes excluding those derived from chromosome 15: II. Review of the literature. Am J Med Genet 1998:75:367-81.

154 Liehr T, Claussen U, Starke H. Small supernumerary marker chromosomes (sSMC) in humans. Cytogenet Genome Res 2004;107:55-67.

155 Kosztolanyi G, Mehes K, Hook EB. Inherited ring chromosomes - an analysis of published cases. Hum Genet 1991:87:320-4.

156 Daniel A. Structural differences in reciprocal translocations. Potential for a model of risk in rcp. Hum Genet 1979a;51:171-82.

157 Morton NE. Parameters of the human genome. Proc Natl Acad Sci $1991 ; 88: 7474-6$.

158 Davis G, James T, Larkins SA, Dyer SA, Gould CP, Thompson DA MacDonald F, Cole T, Davison EV. A large de novo deletion of the long arm of chromosome 10 without apparent clinical effect. J Med Genet 1999;36(suppl 1):3.239.

159 Stumm M, Musebeck J, Tonnies H, Volleth M, Lemke J, Chudoba I, Wieacker P. Partial trisomy 9p12p21.3 with a normal phenotype. J Med Genet 2002;39:141-4

160 Rivera H, Turleau C, de Grouchy J, Junien C, Despoisse S, Zucker J-M. Retinoblastoma-del(13ql4): Report of two patients, one with a trisomic sib due to maternal insertion. Gene-dosage effect for esterase D. Hum Genet 1981;59:211-14.

161 Starke H, Senger G, Kossakiewicz M, Tittelbach H, Rau D, Rubtsov N, Trifonov V, Heller A, Hartmann I, Claussen U, Liehr T. Maternal insertion of $18 q 11.2-q 12.2$ in 18p11.3 of the same chromosome analysed by microdissection and multicolour banding (MCB). Prenat Diagn $2001 ; 21: 1049-52$

162 Shapira SK, McCaskill C, Northrup H, Spikes AS, Elder FFB, Sutton VR, Korenberg JR, Greenberg F, Shaffer LG. Chromosome 1p36 deletions: the clinical phenotype and molecular characterization of a common newly delineated syndrome. Am J Hum Genet 1997;61:642-50.

163 De Vries BB, Winter R, Schinzel A, van Ravenswaaij-Arts C. Telomeres: a diagnosis at the end of the chromosomes. J Med Genet 2003:40:385-98.

164 Riegel M, Baumer A, Jamar M, Delbecque K, Herens C, Verloes A Schinzel A. Submicroscopic terminal deletions and duplications in retarded patients with unclassified malformation syndromes. Hum Genet 2001; 109:286-94.

165 Yamagishi H, Ishii C, Maeda J, Kojima Y, Matsuoka R, Kimura M, Takao A, Momma K, Matsuo N. Phenotypic discordance in monozygotic twins with 22q11.2 deletion. Am J Med Genet 1998;78:319-21

166 Kumar A, Cassidy SB, Romero L, Schwartz S. Molecular cytogenetics of a de novo interstitial deletion of chromosome arm $6 \mathrm{q}$ in a developmentally normal girl. Am J Med Genet 1999;86:227-31.

167 Gilmore L, Cuskelly M, Jobling A, Smith S. Deletion of 8p: a report of a child with normal intelligence. Dev Med Child Neurol 2001;43:843-6.

168 Milunsky JM, Huang XL. Unmasking Kabuki syndrome: chromosome 8p228p23.1 duplication revealed by comparative genomic hybridization and BAC-FISH. Clin Genet 2003;64:509-16.

169 Miyake N, Harada N, Shimokawa O, Ohashi H, Kurosawa K, Matsumoto T, Fukushima Y, Nagai T, Shotelersuk V, Yoshiura K, Ohta T, Kishino T, Niikawa N, Matsumoto N. On the reported 8p22-p23.1 duplication in Kabuki make-up syndrome (KMS) and its absence in patients with typical KMS. Am J Med Genet 2004;128A:170-2.

170 Casamassima AC, Klein RM, Wilmot PL, Brenholz P, Shapiro LR. Deletion of $16 q$ with prolonged survival and unusual radiographic manifestations. Am J Med Genet 1990;37:504-9.

171 Barber JCK. Euchromatic heteromorphism or duplication without phenotypic effect? Prenat Diagn 1994; 14:323-4.

172 Engelen JJ, Die-Smulders, CE de, Vos PT, Meers LE, Albrechts JC, Hamers AJ. Characterizastion of a partial trisomy $16 \mathrm{q}$ with FISH. Report of a patient and review of the literature. Ann Genet 1999;42:101-4.

173 Korenberg JR, Kalousek DK, Anneren G, Pulst S-M, Hall JG, Epstein CJ, Cox DR. Deletion of chromosome 21 and normal intelligence: molecula definition of the lesion. Hum Genet 1991;87:112-18.

174 Daniel A. Case reports: normal phenotype and partial trisomy for the Gpositive region of chromosome 21. J Med Genet 1979b;16:227-9

175 Leana-Cox J, Pangkanon S, Eanet KR, Curtin MS, Wulfsberg EA. Familial DiGeorge/velocardiofacial syndrome with deletions of chromosome area 22q1 1.2: report of five families with a review of the literature. Am J Med Genet 1996;65:309-16.

176 Ritchie JR, Mattei M-G, Lalande M. A large polymorphic repeat in the pericentromeric region of human chromosome $15 q$ contains three partial gene duplications. Hum Mol Genet 1998;8:1253-60.

177 Sugawara H, Harada N, Ida T, Ishida T, Ledbetter DH, Yoshiura K, Ohta T, Kishino T, Niikawa N, Matsumoto N. Complex low-copy repeats associated with a common polymorphic inversion at human chromosome 8p23. Genomics 2003;82:238-44.

178 Sebat J, Lakshmi B, Troge J, Alexander J, Young J, Lundin P, Maner S, Massa H, Walker M, Chi M, Navin N, Lucito R, Healy J, Hicks J, Ye K, Reiner A, Gilliam TC, Trask B, Patterson N, Zetterberg A, Wigler M. 
Large-scale copy number polymorphism in the human genome. Science 2004:305:525-8

179 Barber JCK, Maloney, Hollox EJ, Stuke-Sontheimer A, du Bois G, Daumiller E, Klein-Vogler U, Dufke A, Armour JAL, Liehr T. Duplications and copy number variants of 8 p23.1 are cytogenetically indistinguishable but distinct at the molecular level. Eur J Med Genet, submitted.

180 Spellman RA, Rhodes CH, Wojiski SA, Mohandas TK, Park JP. Molecular cloning studies of chromosome region 9 p 12 reveal homology to proximal 9q; implications for chromosome 9 polymorphisms. J Assoc Genet Technol 1998;24:153.

181 Regnier V, Meddeb M, Lecointre G, Richard F, Duverger A, Nguyen VC, Dutrillaux B, Bernheim A, Danglot $G$. Emergence and scattering of multiple neurofibromatosis (NF1)-related sequences during hominoid evolution suggest a process of pericentromeric interchromosomal transposition. Hum Mol Genet 1997:6:9-16.

182 Eichler EE, Lu F, Shen Y, Antonacci R, Jurecic V, Doggett NA, Moyzis RK, Baldini A, Gibbs RA, Nelson DL. Duplication of a gene-rich cluster between $16 \mathrm{p} 11.1$ and $\mathrm{Xq28}$ : a novel pericentromeric-directed mechanism for paralogous genome evolution. Hum Mol Genet 1996:5:899-913.

183 Eichler EE, Budarf ML, Rocchi M, Deaven LL, Doggett NA, Baldini A, Nelson DL, Mohrenweiser HW. Interchromosomal duplications of the adrenoleukodystrophy locus: a phenomenon of pericentromeric plasticity. Hum Mol Genet 1997:6:991-1002.

184 lafrate AJ, Feuk L, Rivera MN, Listewnik ML, Donahoe PK, Qi Y, Scherer SW Lee $C$. Detection of large-scale variation in the human genome. Nat Genet 2004;36:949-51.

185 Savelyeva L, Claas A, Matzner I, Schlag P, Hofmann W, Scherneck S, Weber B, Schwab M. Constitutional genomic instability with inversions, duplications, and amplifications in 9p23-24 in BRCA2 mutation carriers. Cancer Res 2001;61:5179-85.

186 Horsley SW, Daniels RJ, Anguita E, Raynham HA, Peden JF, Villegas A, Vickers MA, Green S, Waye JS, Chui DHK, Ayyub H, MacCarthy AB, Buckle VJ, Gibbons RJ, Kearney L, Higgs DR. Monosomy for the most telomeric, gene-rich region of the short arm of human chromosome 16 causes minimal phenotypic effects. Eur J Hum Genet 2001;9:217-25.

187 Linden MG, Bender BG. Related. Fifty-one prenatally diagnosed children and adolescents with sex chromosome abnormalities. Am J Med Genet 2002;110:11-18.

$188 \mathrm{Gu}$ X. Evolution of duplicate genes versus genetic robustness against null mutations. Trends Genet 2003;19:354-6.

189 Knight JC. Allele-specific gene expression uncovered. Trends Genet 2004;20:113-16.

190 Bengtsson U, Mcmahon J, Quarrell O, Rubenstein C, David K, Greenberg F, Wasmuth JJ. Phenotypically normal carriers of unbalanced terminal deletions of $5 p$ transmit the deletions to offspring who display growth and developmental delay. Am J Hum Genet 1990;47(suppl):A818.

191 Biesecker LG. The end of the beginning of chromosome ends. Am J Med Genet 2002;107:263-6.

192 Harada N, Hatchwell E, Okamoto N, Tsukahara M, Kurosawa K, Kawame H, Kondoh T, Ohashi H, Tsukino R, Kondoh Y, Shimokawa O, Ida T, Nagai T, Fukushima Y, Yoshiura K, Niikawa N, Matsumoto N. Subtelomere specific microarray based comparative genomic hybridisation: a rapid detection system for cryptic rearrangements in idiopathic mental retardation. $J$ Med Genet 2004;41:130-6.

193 Buckland PR. Polymorphically duplicated genes: their relevance to phenotypic variation in humans. Ann Med 2003;35:308-15
194 Hirotsune S, Yoshida N, Chen A, Garrett L, Sugiyama F, Takahashi S, Yagami K, Wynshaw-Boris A, Yoshiki A. An expressed pseudogene regulates the messenger-RNA stability of its homologous coding gene. Nature 2003;423:91-6.

195 Ji Y, Eichler E, Schwartz S, Nicholls RD. Structure of chromosomal duplicons and their role in mediating human genomic disorders. Genome Res 2000;10:597-610.

196 Bailey JA, Gu Z, Clark RA, Reinert K, Samonte RV, Schwartz S, Adams MD, Myers EW, Li PW, Eichler EE. Recent segmental duplications in the human genome. Science 2002;297:1003-7.

197 Giglio S, Broman KW, Matsumoto N, Calvari V, Gimelli G, Neumann T, Ohashi $H$, Voullaire L, Larizza D, Giorda R, Weber JL, Ledbetter DH, Zuffardi $O$. Olfactory receptor-gene clusters, genomic-inversion polymorphisms, and common chromosome rearrangements. Am J Hum Genet $2001 ; 68: 874-83$.

198 Giglio S, Calvari V, Gregato G, Gimelli G, Camanini S, Giorda R, Ragusa A, Guerneri S, Selicorni A, Stumm M, Tonnies H, Ventura M, Zollino M, Neri G, Barber J, Wieczorek D, Rocchi M, Zuffardi O. Heterozygous submicroscopic inversions involving olfactory receptor-gene clusters mediate the recurrent $t(4 ; 8)($ p16;p23) translocation. Am J Hum Genet 2002;71:276-85.

199 Bailey JA, Baertsch R, Kent WJ, Haussler D, Eichler EE. Hotspots of mammalian chromosomal evolution. Genome Biol 2004;5:R23

200 Chandley AC. Meiotic studies and fertility in human translocation carriers. In: Daniel A, ed. The cytogenetics of mammalian autosomal rearrangements. New York: Alan R Liss, 1988:361-82.

201 Mitelman F, ed. ISCN 1995: An international system for human cytogenetic nomenclature. Basel: Karger, 1995.

202 Lindsley DL, Sandler L, Baker BS, Carpenter ATC, Denell RE, Hall JC, Jacobs PA, Miklos GLG, Davis BK, Gethmann RC, Hardy RW, Hessler A, Miller SM, Nozawa H, Parry DM, Gould-Somero M. Segmental aneuploidy and the genetic gross structure of the Drosophila genome. Genetics 1972;11:157-84.

203 Epstein CJ. The consequences of chromosomal imbalance. Cambridge: Cambridge University Press, 1986:39-42.

204 Epstein CJ. The pathogenesis of aneuploid phenotypes: the fallacy of explanatory reductionism. Am J Med Genet 1988;33:151.

205 Shapiro BL. Letter to the Editor: The pathogenesis of aneuploid phenotypes: the fallacy of explanatory reductionism. Am J Hum Genet 1989;33:146-150.

206 Wilson GN. Karyotype/phenotype controversy: genetic and molecular implications of alternative hypotheses. Am J Med Genet 1990b;36:500-5.

207 Wilson GN, Heller KB, Elterman RD, Schneider NR. Partial trisomy 18 with minimal anomalies: lack of correspondence between phenotypic manifestations and triplicated loci along chromosome 18. Am J Med Genet 1990;36:506-10.

208 Korenberg JR, Chen X-N, Schipper R, Sun Z, Gonsky R, Gerwehr S, Carpenter N, Daumer C, Dignan P, Disteche C, Graham JM Jr, Hugdfins L, McGillivray B, Miyazaki K, Ogasawara N, Park JP, Pagon R, Pueschel S, Sack G, Say B, Schuffenhauer S, Soukup S, Yamanaka T. Down syndrome phenotypes: the consequences of chromosomal imbalance. Proc Natl Acad Sci USA 1994:91:4997-5001.

209 FitzPatrick DR, Ramsay J, McGill NI, Shade M, Carothers AD, Hastie ND. Transcriptome analysis of human autosomal trisomy. Hum Molec Genet 2002;113:249-56.

210 Cody JD, Hale DE. Precision in phenotyping and genotyping. Am J Med Genet 2004;131A:313. 


\begin{tabular}{|c|c|c|c|c|c|c|c|}
\hline & Region & Size & Con & Ascertainment & Mode & c & Ref \\
\hline \multicolumn{8}{|l|}{ del } \\
\hline 2 & p12-p12 & 6.1 & $F, M$ & PD Previous +18 & Mat & 5 & Family $1^{1}$ \\
\hline 2 & p12-p12 & 6.9 & $F, M$ & PD Maternal age & Both & 3 & Family $2^{1}$ \\
\hline 2 & q13-q14.1 & 6.0 & $\mathrm{~F}$ & MC Miscarriages & Mat & 2 & 2 \\
\hline 3 & p25.3-pter & 10.1 & $\mathrm{~F}$ & PD Maternal age & Mat & 2 & 3 \\
\hline 5 & pl4-pl4 & 13.8 & M & PD Maternal age & Mat & 6 & 4 \\
\hline 8 & p23.1/2-pter & 6.1 & $\mathrm{~F}$ & PD Maternal age & Pat & 2 & 5 \\
\hline 8 & $q 24.13 q 24.22$ & 4.2 & $P, F$ & PD Triple screen & Mat & 2 & 6 \\
\hline 9 & p21.2-p22.1 & 7.6 & - & PD Maternal age & Both & 3 & 7 \\
\hline 10 & $q 11.2 q 21.2$ & 13.3 & $P$ & MC Miscarriages & $N$ & 1 & 158 \\
\hline 11 & pl2 & 6.1 & - & PD Maternal age & Mat & 3 & 8 \\
\hline 13 & $q 21-q 21$ & 16.0 & - & MC Miscarriages & Mat & 2 & 9 \\
\hline 16 & $q 13 q 22$ & 7.0 & $\mathrm{~F}$ & PD Maternal age & Mat & 3 & 10 \\
\hline 16 & $q 21-q 21$ & 7.0 & M & PD Maternal age & Pat & 3 & 11 \\
\hline 18 & p11.31-pter & $\begin{array}{l}4.4 \\
4 \times 8 ?\end{array}$ & - & PD Serum AFP & Pat & 2 & 12 \\
\hline \multicolumn{8}{|l|}{ dup } \\
\hline 1 & p21-p31 & 31.3 & $\mathrm{~F}$ & PD Maternal age & Mat & 2 & 13 \\
\hline 3 & $q 28-q 29$ & 8.6 & $P$ & PD Maternal age & Pat & 3 & 12 \\
\hline 8 & p23.1-p23.3 & 6.1 & $\mathrm{~F}$ & I Oligoasthenospermia & Mat & 3 & 14 \\
\hline 8 & p22 & 3.4 & $F$ & PD Triple screen & Both & 3 & 15 \\
\hline 10 & p13-p14 & 5.3 & $F$ & PD Low serum screen & Mat & 3 & 16 \\
\hline 13 & q14-q21 & 18.3 & $\mathrm{~F}$ & PD Maternal hyposomia & Mat & 2 & 17 \\
\hline 18 & pl1.2-pter & $\begin{array}{l}22.0 \\
\text { Av } 13.6\end{array}$ & M & PD Raised seurm AFP & Mat & 2 & 18 \\
\hline \multicolumn{8}{|c|}{ AV 10.0} \\
\hline $\begin{array}{l}\operatorname{der}(5) \\
\text { ins }(5 ; 9)\end{array}$ & $\operatorname{dup}(9)(p 12-p 21.3)$ & 21.0 & $P, F$ & PA*Phenotype of daughter & $\mathrm{N}$ & 1 & 159 \\
\hline $\operatorname{der}(20)$ & $\operatorname{dup}(13)(q 13-q 14.3)$ & 11.6 & B & $\mathrm{PA}^{*}$ Phenotype of sibling & $\mathrm{N}$ & 1 & 160 \\
\hline $\begin{array}{l}\operatorname{der}(18) \\
\text { inc }(18.18)\end{array}$ & $\operatorname{dup}(18)(q 11.2 q 12.2)$ & 10.0 & $\mathrm{~F}$ & PD FH Down's syndrome & $\mathrm{N}$ & 1 & 161 \\
\hline $\begin{array}{l}\text { der(1); } \\
t(1 ; ?)\end{array}$ & del 1p32-pter dup? & 48.5 & - & PD Maternal age & Pat & 2 & 19 \\
\hline $\begin{array}{l}\operatorname{der}(6) \\
t(6 ; 21)\end{array}$ & $\begin{array}{l}\text { del ?6p25-pter \& } \\
\text { ?21q11-pter }\end{array}$ & - & - & $\mathrm{PA}^{*}$ Phenotype of sibling & Mat & 4 & 20 \\
\hline $\begin{array}{l}\operatorname{der}(9) \\
t(9 ; 22)\end{array}$ & $\begin{array}{l}\text { del 22q11.21-pter } \\
\text { (9q subtel intact) }\end{array}$ & $\begin{array}{l}4.1 \\
0.0\end{array}$ & $\mathrm{~F}$ & PD Maternal age & Mat & 4 & 21 \\
\hline Totals & 27 families & & $21 / 27$ & $\begin{array}{l}\mathrm{PD} 20 / 27 ; \text { MC } 3 / 27 \\
\mathrm{PA}^{*} 3 / 27 ; 11 / 23\end{array}$ & $\begin{array}{l}\text { Mat } 15 / 23 \text {; } \\
\text { pat } 5 / 23 \text {; } \\
\text { both } 3 / 23\end{array}$ & 70 & 8 Abstract only \\
\hline
\end{tabular}




\begin{tabular}{|c|c|c|c|c|c|c|c|}
\hline & Region & Size & Con & Ascertainment & Mode & C & Ref \\
\hline \multicolumn{8}{|l|}{ del } \\
\hline 5 & p15.2-pter & 9.6 & $\mathrm{~F}, \mathrm{M}$ & PA Cat cry, microcephaly & Mat & 2 & Family $3^{22}$ \\
\hline 5 & p15.3-pter & 8.1 & $\mathrm{~F}, \mathrm{M}$ & PA Low birth weight, microcephaly & Pat & 4 & Family $4^{22}$ \\
\hline 5 & pl4.1-pl4.3 & 9.4 & $P$ & PA Peroxisomal disorder & Mat & 2 & 10 \\
\hline 5 & pl4-pl4 & 6.4 & $\mathrm{~F}$ & PA Dev delay, microcephaly, seizures & $\mathrm{Pat}^{\mathrm{m}}$ & 2 & 23 \\
\hline 7 & p22-pter & 5.5 & - & PA Patient on Intensive Care Unit & Mat & 3 & 24 \\
\hline 11 & q14.3-ql4.3 & 3.6 & - & PA Dev delay & Pat & 5 & 25 \\
\hline 13 & q14-ql4 & $\begin{array}{l}10.0 \\
A v 7.5\end{array}$ & M & PA Retinoblastoma & Mat & 2 & 26 \\
\hline \multicolumn{8}{|l|}{ dup } \\
\hline 1 & q11-q22 & 11.4 & $\mathrm{~F}$ & L Leukaemia & Mat & 3 & 27 \\
\hline 1 & $q 42.11-q 42.12$ & 4.1 & - & PA Short stature & Mat & 2 & 28 \\
\hline 3 & $q 25-q 25$ & 10.4 & - & PA Dysmorphic, CHD & Both & 5 & 29 \\
\hline 4 & q31.3-q33 & 10.6 & $P$ & $\mathrm{PA}^{*}$ Trisomy 21 in proband & Mat & 3 & 30 \\
\hline 5 & q15-q21 & 16.3 & $\mathrm{~F}$ & PD Cystic hygroma on ultrasound & Pat & 3 & 31 \\
\hline 6 & $q 24.2-q 24.2$ & 2.0 & $\mathrm{~F}$ & PA Transient Neonatal Diabetes & Pat & 2 & 21 \\
\hline 8 & p23.2-p23.2 & 2.5 & $\mathrm{~F}$ & PA Short stature & Mat & 2 & Family $2^{32}$ \\
\hline 8 & p23.2-p23.2 & 2.5 & $\mathrm{~F}$ & PA Dysmorphic features & Pat & 2 & Family $3^{32}$ \\
\hline 8 & p23.2-p23.2 & 2.5 & $\mathrm{~F}$ & PA Dev delay, inguinal testis & Mat & 2 & Family $4^{32}$ \\
\hline 8 & p23.1-p23.1 & 6.5 & - & PA Dysmorphic & Pat & 2 & Family $1^{33}$ \\
\hline 8 & p23.1-p23.1 & 6.5 & - & PA MCA & Mat & 2 & Family $7^{33}$ \\
\hline 8 & p23.1-p23.1 & 6.5 & - & PA Autistic behaviour & Mat & 2 & Family $8^{33}$ \\
\hline 14 & q24.3-q31 & 9.8 & $\mathrm{~F}$ & PA Dev delay & Pat & 2 & 34 \\
\hline 15 & q11-q13 & 4.0 & $M$ & PA Dev delay, ?fragile $X$ & Mat & 3 & Family $1^{35}$ \\
\hline 15 & $q 11-q 12$ & 4.0 & $F$ & PA Dev delay & Mat & 2 & 36 \\
\hline 15 & q11-q13 & 4.0 & $M$ & PA Autism & Mat $^{*}$ & 3 & 37 \\
\hline 15 & q11-q13 & 4.0 & M & PA Dev delay & Mat $^{*}$ & 2 & 38 \\
\hline 15 & q11-q13 & 4.0 & - & PA Autism & $\mathrm{Mat}^{*}$ & 2 & 39 \\
\hline 16 & $q 12.1-q 12.1$ & $\begin{array}{c}5.1 \\
\text { Av } 6.1\end{array}$ & $\mathrm{~F}$ & PA Autism & Mat & 2 & 40 \\
\hline \multicolumn{8}{|l|}{ der } \\
\hline $\begin{array}{l}\operatorname{der}(2) \\
\text { ins }(2 ; 6)\end{array}$ & dup 6q23.3-q24.2 & 8.1 & $\mathrm{~F}, \mathrm{M}$ & PA TNDM & Both & 3 & 41 \\
\hline $\operatorname{der}(11)$ & del 11q25-qter & - & & I Infertility & Pat & 2 & 42 \\
\hline$t(11 ; 15)$ & del 15q11-pter & - & - & & & & \\
\hline $\operatorname{der}(11)$ & del 11 q25-qter & - & - & PA Unusual facies, physical \& mental & Mat & 4 & 43 \\
\hline$t(11 ; 22)$ & del 22q11-pter & - & & retardation & & & \\
\hline $\operatorname{der}(21)$ & del 19p13-pter & - & - & PA* Down's syndrome in one of twins & Mat & 3 & 44 \\
\hline $\begin{array}{l}\text { fotals } \\
\text { Total }\end{array}$ & $\begin{array}{l}\text { del } 21 \text { q } 21.1-\text { pter } \\
30\end{array}$ & - & $19 / 30$ & $\begin{array}{l}\text { PA } 25 / 30 ; P^{*} 2 / 30 ; P D 1 / 30 ; \\
\text { I } 1 / 30 ; \text { L } 1 / 30\end{array}$ & $\begin{array}{l}\text { Mat } 16 / 30 \text {; } \\
\text { mat }^{*} 3 / 30 \text {; } \\
\text { pat } 9 / 30 \text {; } \\
\text { both } 2 / 30\end{array}$ & 78 & 2 Abstract only \\
\hline
\end{tabular}




\begin{tabular}{|c|c|c|c|c|c|c|c|}
\hline & Region & Size & Con & Ascertainment & Mode & c & Ref \\
\hline \multicolumn{8}{|l|}{ del } \\
\hline 1 & $q 42.1-q 42.3$ & 7.1 & $\mathrm{P}$ & PA Dev delay, ADD & Mat & 2 & 45 \\
\hline 2 & p11.2-p12 & 7.5 & $F, M$ & PA Wilm, stumour, dev delay & Mat & 2 & Family $3^{\prime}$ \\
\hline 3 & p25-pter & 9.1 & - & PA Speech delay & Mat & 2 & 46 \\
\hline 4 & p15.2-p16.1 & 15.9 & - & PA & Mat & 2 & 47 \\
\hline 4 & q33-qter & 18.6 & $F$ & PA MCA inc macrocephaly and language delay & Mat & 2 & 48 \\
\hline 4 & q33-q35.1 & 13.3 & - & PA Dev delay & Mat & 3 & 49 \\
\hline 4 & q33-q33 & 2.7 & - & PA Dev delay and dysmorphic features & Mat & 2 & Family $1^{50}$ \\
\hline 4 & $q 32-q 33$ & 8.0 & - & PA Dev delay and dysmorphic features & Mat & 2 & Family $2^{50}$ \\
\hline 5 & p15.32-pter & 9.5 & - & PA Dev motor, speech delay & Mat & 4 & 51 \\
\hline 5 & p15.31-pter & 9.5 & $\mathrm{~F}$ & PA Speech delay, dysmorphic & Pat & 4 & 52 \\
\hline 5 & p15.3-pter & 8.2 & $\mathrm{~F}$ & PA Cat cry at birth, low birth weight & Pat & 4 & 53 \\
\hline 5 & p15.3-pter & 9.5 & M & PA Speech delay, hearing loss, mild MR & Both & 3 & Family $\left.\right|^{54}$ \\
\hline 5 & p15.3-pter & 9.5 & M & PA Speech delay, mild dev delay & Mat & 2 & Family $\|^{54}$ \\
\hline 5 & p15.3-pter & 8.7 & M & PA Speech delay, raspy voice & Mat & 3 & Family III ${ }^{54}$ \\
\hline 5 & p15.3-pter & 8.7 & M & PA Speech and dev delay & Both & 6 & Family IV ${ }^{54}$ \\
\hline 5 & p15.1-pter & 13.6 & - & PA MCA & Mat & 2 & 55 \\
\hline 5 & p14-p15.3 & 20.4 & - & PA Cri-du-chat & Mat & 2 & 56 \\
\hline 5 & p13.3-p14.3 & 13.6 & & PA Microcephaly, small & Mat & 4 & 57 \\
\hline 5 & p13.1-p14.2 & 8.2 & M & PA Speech delay & Both & 6 & 21 \\
\hline 5 & p13-p15.1 & 17.0 & - & PD Maternal age & Mat & 4 & 58 \\
\hline 8 & p23.1-pter & 6.2 & $\mathrm{~F}$ & PA Mental slowness, behaviour, seizures & Pat & 3 & 59 \\
\hline 9 & $q 31.2-q 32$ & 3.2 & - & PA Dev dela, FTT, unusual appearance & $M a t^{m}$ & 2 & 60 \\
\hline 11 & q24.2-qter & 9.6 & - & PA Dev delay & Mat & 2 & 61 \\
\hline 13 & q14.1-q21.3 & 19.9 & B & PA Leukocoría & Mat & 2 & 62 \\
\hline 14 & q31-q31 & 8.2 & M & PA Dev delay & Both & 4 & 63 \\
\hline 15 & $q 11-q 12$ & 2.0 & M & PA MR & Mat & 2 & 64 \\
\hline 18 & p11.3-pter & 5.7 & $F, P$ & PD Previous son with MR & Mat & 2 & 65 \\
\hline 18 & p11.21-pter & 12.9 & - & PA MR; short stature & Mat & 2 & 66 \\
\hline 18 & pl1.2-pter & 14.3 & $\mathrm{P}$ & PD Abnormal ultrasound & Mat & 2 & 67 \\
\hline 18 & pl1.23-pter & 7.2 & $\mathrm{P}$ & PA MCA & Mat & 3 & 68 \\
\hline 18 & pl1.2-pter & 14.3 & $\mathrm{~F}$ & PA MR, short stature & Mat & 2 & 69 \\
\hline 18 & $\mathrm{p}$ (pre-banding) & 20.1 & - & PA Failure to thrive, ptosis & $\mathrm{Mat}^{\mathrm{m}}$ & 3 & 70 \\
\hline 18 & q23-qter & 5.7 & M & PA Dysmorphic & Mat & 2 & 71 \\
\hline 18 & ?q21-qter & 30.8 & - & PA MCA & Mat & 5 & 72 \\
\hline 18 & q22.3-qter & 8.6 & - & PA & Mat & 2 & 73 \\
\hline 20 & pl1.2-p12.2 & 5.8 & - & PA Dysmorphic & Mat & 2 & 74 \\
\hline 21 & $q 11-q 21.3$ & 17.3 & M & PA Dislocated hips & Mat & 2 & 75 \\
\hline 22 & q11.2-q11.2 & 2.0 & M & PA Cardiac failure & Mat & 4 & 76 \\
\hline Subtotal & 38 families & Av 10.9 & $21 / 38$ & PA $35 / 38 ;$ PD $3 / 38$ & $\begin{array}{l}\text { Mat } 32 / 38 \text {; } \\
\text { pat } 3 / 38 \\
\text { both } 4 / 38\end{array}$ & 107 & $\begin{array}{l}\text { 6/38 Abstracts } \\
\text { only }\end{array}$ \\
\hline \multicolumn{8}{|l|}{ dup } \\
\hline 1 & q23-q25 & 15.7 & - & PA Mild MR and dysmorphism & Mat & 2 & Family $A^{77}$ \\
\hline 3 & $q 25.3-q 26.2$ & 17.0 & $F$ & PA Microcephaly; CHD and deafness & Both & 9 & 78 \\
\hline 4 & $q 31.22-q 33$ & 19.5 & - & PA Mild MR and dysmorphism & Mat & 2 & Family $B^{77}$ \\
\hline 4 & $q 31.1-q 32.3$ & 18.6 & $\mathrm{~F}$ & PA Dev delay, nasal speech & Mat & 3 & 79 \\
\hline 5 & q15-q22.1 & 13.6 & - & PA Hyperactive, mild MR & Mat & 2 & 80 \\
\hline 7 & $\mathrm{p} 12.2-\mathrm{p} 13$ & 5.5 & $\mathrm{~F}$ & PA Failure to thrive & Mat & 4 & 81 \\
\hline 7 & p12.1-p13 & 6.9 & $F, M$ & PA Short stature, ?Silver-Russell & Mat & 2 & 82 \\
\hline 7 & q32-q36.1 & 17.8 & - & PA Dev delay, behavioural problems & Mat & 2 & 83 \\
\hline 8 & p23.1-p23.1 & 6.5 & $\mathrm{P}$ & PA CHD & $\mathrm{Pat}^{\mathrm{m}}$ & 2 & 84 \\
\hline 8 & p23.1-p23.1 & 6.5 & - & PA Dev delay & Mat & 3 & Family $3^{33}$ \\
\hline 8 & p23.1-p23.1 & 6.5 & - & PA* Dev delay, hypotonia, (PWS) & Pat & 2 & Family $4^{33}$ \\
\hline 8 & p22-p23.1 & 9.6 & $\mathrm{~F}$ & PA Mild MR only & Mat & 3 & 85 \\
\hline 8 & p21.3-p23.1 & 9.6 & $\mathrm{P}$ & PA CHD & Mat & 3 & Family $1^{86}$ \\
\hline 8 & p21.3-p23.1 & 9.6 & $\mathrm{P}$ & PA Speech delay & Pat & 3 & Family $2^{86}$ \\
\hline 8 & p21.3-p22 or p22-p23.1 & 9.6 & $\mathrm{P}$ & PA MR, short stature, hypertelorism & Mat & 3 & 87 \\
\hline 8 & p12-p21.1 & 6.9 & $F, B$ & PA Dev delay & Mat & 4 & 88 \\
\hline 9 & p22-p24 & 11.4 & $\mathrm{~F}$ & PA Short, low IQ, dysmorphic & Pat & 2 & 89 \\
\hline 10 & p13-p15 & 4.0 & $\mathrm{~F}$ & PA Dev delay especially speech & Both & 6 & 90 \\
\hline 11 & $q 13.5-q 21$ or $q 21-q 23.1$ & 13.8 & $\mathrm{~F}$ & PD Maternal age & Mat & 2 & 91 \\
\hline 14 & q13-q22 & 26.1 & $\mathrm{P}$ & PA Dev delay & Mat & 3 & 92 \\
\hline 15 & $q 11.2-q 13$ & 4.0 & M & PA Dev delay, hypogonadism & Mat $^{*}$ & 6 & Family $2^{35}$ \\
\hline 15 & q11.2-q13 & 4.0 & M & PA Severe MR & Mat $^{*}$ & 3 & Family $3^{35}$ \\
\hline 15 & q11.2-q13 & 4.0 & M & PA Dev delay & Mat $^{*}$ & 5 & Family $4^{35}$ \\
\hline 15 & q11-q13 & 4.0 & $F+M$ & PA Dev delay & Mat & 6 & Family $A^{93}$ \\
\hline 16 & q11.2-q12.1 & 5.1 & $\mathrm{~F}$ & PA Speech delay & Pat & 4 & Family $2^{94}$ \\
\hline 18 & cen-pter & 21.5 & $\mathrm{~F}$ & PA Dysmorphic, moderate MR & $\mathrm{Mat}^{\mathrm{m}}$ & 2 & 95 \\
\hline 21 & q22-qter & 18.3 & $\mathrm{~F}$ & PA Unusual appearance & Mat & 3 & 21 \\
\hline Subtotal & 27 families & Av 10.9 & $21 / 27$ & PA 25/27; PA* 1/26; PD $1 / 26$ & $\begin{array}{l}\text { Mat 20/27; } \\
\text { pat 5/27; }\end{array}$ & 191 & $\begin{array}{l}3 / 27 \text { Abstracts } \\
\text { only }\end{array}$ \\
\hline \multicolumn{8}{|l|}{ der } \\
\hline $\operatorname{der}(8)$ & dup 2q11.2-q21.1 & 28.1 & $\mathrm{P}$ & PA Unusual facies, language delay & Mat & 2 & 96 \\
\hline ins(8;2) & & & $\mathrm{F}$ & PA Mitral valve prolanse & & 2 & 97 \\
\hline $\begin{array}{l}\text { ins(7;22) } \\
\operatorname{der}(9)\end{array}$ & $\begin{array}{l}\text { del 22q13.3 } \\
\text { dup 10p14-p15 }\end{array}$ & $\overline{15.0}$ & $F, M$ & $\begin{array}{l}\text { PA Mitral valve prolapse } \\
\text { PA MCA }\end{array}$ & Pat & 3 & 98 \\
\hline $\begin{array}{l}\operatorname{ins}(9 ; 10) \\
\operatorname{der}(16) \\
\operatorname{ins}(16 ; 16)\end{array}$ & dup q11.2-q13.1 & 11.9 & $\mathrm{~F}$ & PA Dev delay & Mat $^{m}$ & 3 & Family $1^{94}$ \\
\hline
\end{tabular}




\begin{tabular}{|c|c|c|c|c|c|c|c|}
\hline & Region & Size & Con & Ascertainment & Mode & c & Ref \\
\hline $\begin{array}{l}\operatorname{der}(4) \\
t(4 ; 5)\end{array}$ & $\begin{array}{l}\text { del } 4 q 34 \text {-qter; dup } \\
5 \text { p15.1-pter }\end{array}$ & $\begin{array}{l}13.3 \\
15.0\end{array}$ & $\mathrm{~F}$ & PA MR, dysmorphic & Mat & 2 & 99 \\
\hline$t(4 ; 14)$ & del 4 or 14 & 10.0 & M & PA Genital and retinal abnormalities & Pat & 2 & 100 \\
\hline $\begin{array}{l}\operatorname{der}(4) \\
t(4 ; 22)\end{array}$ & $\begin{array}{l}\text { del } 4 q 35.2 \text {-qter; del } \\
22 \text { q1 1.2-pter }\end{array}$ & $\begin{array}{r}1.3 \\
12.4\end{array}$ & - & PA CHD, dysmorphism & Mat & 2 & 101 \\
\hline $\begin{array}{l}\operatorname{der}(5) \\
t(5 ; ?)\end{array}$ & $\begin{array}{l}\text { del 5p15.32-pter; } \\
\text { dup? }\end{array}$ & $\begin{array}{l}6.8 \\
-\end{array}$ & $F$ & PA ?Cri-du-chat & Both & 4 & 102 \\
\hline $\begin{array}{l}\operatorname{der}(10) \\
t(5 ; 10)\end{array}$ & $\begin{array}{l}\text { dup 5q35-qter; del } \\
10 \text { q26.13-qter }\end{array}$ & $\begin{array}{l}3.4 \\
6.6\end{array}$ & $\mathrm{~F}$ & PA Dysmorphic & Mat & 2 & Family $1^{103}$ \\
\hline $\begin{array}{l}\operatorname{der}(22) \\
t(21 ; 22)\end{array}$ & del 21q21.2-pter & 21.6 & $\mathrm{~F}$ & $\mathrm{PA}^{*}$ Sibling with Down's syndrome & Mat & 5 & 104 \\
\hline $\begin{array}{l}\text { der }(20) \\
t(6 ; 20)\end{array}$ & $\begin{array}{l}\text { dup 6p23-pter; del } \\
20 \text { p13-pter }\end{array}$ & $\begin{array}{r}17.4 \\
4.4\end{array}$ & $\mathrm{~F}$ & PA Dev delay, dysmorphic features & Pat & 2 & 105 \\
\hline $\begin{array}{l}\operatorname{der}(Y) \\
t(Y ; 8)\end{array}$ & dup 8p22-pter & 17.8 & $\mathrm{P}$ & MC Miscarriages $\times 3$ & Pat & 3 & 106 \\
\hline Subtotal & 12 families & & $11 / 12$ & $\mathrm{PA} 10 / 12 ; \mathrm{MC} 1 / 12 ; \mathrm{PA}^{*} 1 / 12$ & $\begin{array}{l}\text { Mat } 6 / 12 \text {; } \\
\text { pat } 5 / 12 \text {; } \\
\text { both } 1 / 12\end{array}$ & 132 & $\begin{array}{l}\text { 1/12 Abstracts } \\
\text { only }\end{array}$ \\
\hline Totals & 77 families & & $53 / 77$ & PA 71/77; PA* 1/77; PD 4/77; MC 1/77 & $\begin{array}{l}\text { Mat } 58 / 77 \text {; } \\
\text { pat } 12 / 77 \text {; } \\
\text { both } 7 / 77\end{array}$ & 230 & $\begin{array}{l}\text { 10/77 Abstracts } \\
\text { only }\end{array}$ \\
\hline
\end{tabular}

Entries in italics are abstracts only. Abbreviations: Con, confirmed with FISH and/or CGH (F); chromosome paint only (P) molecular analysis (M) or biochemistry (B); C, number of carriers in family; PD, prenatal diagnosis; PA, phenotypic abnormality; PA*, phenotypic abnormality due to another identified cause; $M C$, miscarriage; I, infertility; Mat, maternal; Pat, paternal; Both, maternal and paternal transmission; ${ }^{m}$, mosaic.

\begin{tabular}{|c|c|c|c|c|c|c|}
\hline & Region & Con & Ascertainment & Mode & c & Reference \\
\hline 8 & p23.1 & $\mathrm{P}$ & PD Maternal age & Pat & 2 & 107 \\
\hline 8 & p23.1 & $\mathrm{F}$ & MC Miscarriages & Mat & 6 & $\begin{array}{l}\text { Family } 1^{108} \\
\text { Family } 1^{109}\end{array}$ \\
\hline 8 & p23.1 & $\mathrm{F}$ & PD Maternal age & Pat & 3 & Family $2^{108}$ \\
\hline 8 & p23.1 & - & PD Maternal age & Both & 4 & Family $4^{108}$ \\
\hline 8 & p23.1 & - & $P D$ SIR & Pat & 2 & Case $7^{110}$ \\
\hline 8 & p23.1 & - & $P D$ & Pat & 2 & Family $7^{111}$ \\
\hline 8 & p23.1 & - & $P D$ & Pat & 2 & Family $2^{111}$ \\
\hline 8 & p23.1 & - & $P D$ & Mat & 2 & Family $3^{111}$ \\
\hline 9 & p12 & - & PD Previous NTD & Both & 4 & Family $1^{112}$ \\
\hline 9 & p12 & - & PD Previous NTD & Mat & 2 & Family $2^{112}$ \\
\hline 9 & p12 & - & PD Previous NTD & Mat & 3 & Family $3^{112}$ \\
\hline 9 & p11.2-p12 & - & NS Newborn survey & Mat & 2 & 113 \\
\hline 9 & p1 1.2-p12 & - & PD Previous +21 & Pat & 2 & Family $1^{114}$ \\
\hline 9 & p11.2-p12 & - & PD Maternal age & Mat & 5 & Family $2^{114}$ \\
\hline 9 & q12/qh & $\mathrm{F}$ & PD Maternal age & Pat & 2 & 115 \\
\hline 9 & ql2/qh & - & PA* Down's syndrome & Pat & 2 & 116 \\
\hline 9 & q12/gh & - & PD Maternal age & Mat & 2 & 117 \\
\hline 9 & q12/gh & - & MC Miscarriages & Pat & 2 & Family $1^{118}$ \\
\hline 9 & q12/gh & - & PD Maternal age & Pat & 2 & Family $2^{118}$ \\
\hline 9 & q12/gh & - & $\mathrm{PA}^{*}$ Trisomy 21 in sibling & Mat & 3 & 119 \\
\hline 15 & $\mathrm{q} 11.2 \mathrm{v}$ & $\mathrm{F}$ & SB Pregnancy loss & Mat & 3 & Family $A^{120}$ \\
\hline 15 & $\mathrm{q} 11.2 \mathrm{v}$ & $\mathrm{F}$ & PD & Mat & 2 & Family $C^{120}$ \\
\hline 15 & $\mathrm{q} 11.2 \mathrm{v}$ & $\mathrm{F}$ & PD & Pat & 2 & Family D ${ }^{120}$ \\
\hline 15 & ql1.2v & $\mathrm{F}$ & PD & Mat & 2 & Family $\mathrm{E}^{120}$ \\
\hline 15 & $\mathrm{q} 11.2-\mathrm{q} 13$ & M & PD Serum increased risk & Mat & 2 & Family $16^{121}$ \\
\hline 15 & q11.2-q13 & M & PD Serum increased risk & Mat & 2 & Family $17^{121}$ \\
\hline 15 & $\mathrm{q} 11.2-\mathrm{q} 13$ & M & PD Maternal age & Pat & 3 & Family $18^{121}$ \\
\hline 15 & q11.2-q13 & M & PD Raised AFP & Both & 3 & Family $19^{121}$ \\
\hline 15 & $\mathrm{q} 11.2$-q13 & M & PD Serum increased risk & Pat & 3 & Family $20^{121}$ \\
\hline 15 & $\mathrm{q} 11.2 \rightarrow \mathrm{q} 13$ & $\mathrm{P}$ & PD Maternal age & Pat & 2 & 122 \\
\hline 16 & p $11.2 \mathrm{v}$ & $\mathrm{F}$ & MC Miscarriages & Mat & 2 & Case $1^{123}$ \\
\hline 16 & pll & - & MC Miscarriages and stillbirth & Mat & 2 & Family $1^{124}$ \\
\hline 16 & pll & - & PD Not recorded & Pat & 2 & Family $2^{124}$ \\
\hline 16 & pll & - & PD Maternal age & Mat & 4 & 125 \\
\hline 16 & pll & - & PD Maternal age & Mat & 2 & 126 \\
\hline 16 & pl1 & - & PD Parental anxiety & Mat & 2 & 127 \\
\hline 16 & pll & - & PD FH NTD & Pat & 2 & Case $1^{128}$ \\
\hline 16 & pl1 & - & PD Maternal age & Pat & 2 & Case $2^{128}$ \\
\hline Total & 38 & $15 / 38$ & $\begin{array}{l}\text { PD } 30 / 38 ; M C ~ 4 / 38 ; P^{*} 2 / 38 \\
\text { SB } 1 / 38 ; \text { NS } 1 / 38\end{array}$ & $\begin{array}{l}\text { 18/38 Mat; } \\
\text { 17/38 Pat; } \\
3 / 38 \text { Both }\end{array}$ & 94 & 4/38 Abstracts only \\
\hline
\end{tabular}

Entries in italics are abstracts only. Con, confirmed with FISH and/or CGH (F); chromosome paint only (P) or molecular analysis (M); C, number of carriers in family; PD, prenatal diagnosis; PA, phenotypic abnormality; PA*, phenotypic abnormality due to another identified cause; $M C$, miscarriage; SB, stillbirth; I, infertility; Mat, maternal; Pat, paternal; Both, maternal and paternal transmission; ${ }^{m}$, mosaic. 


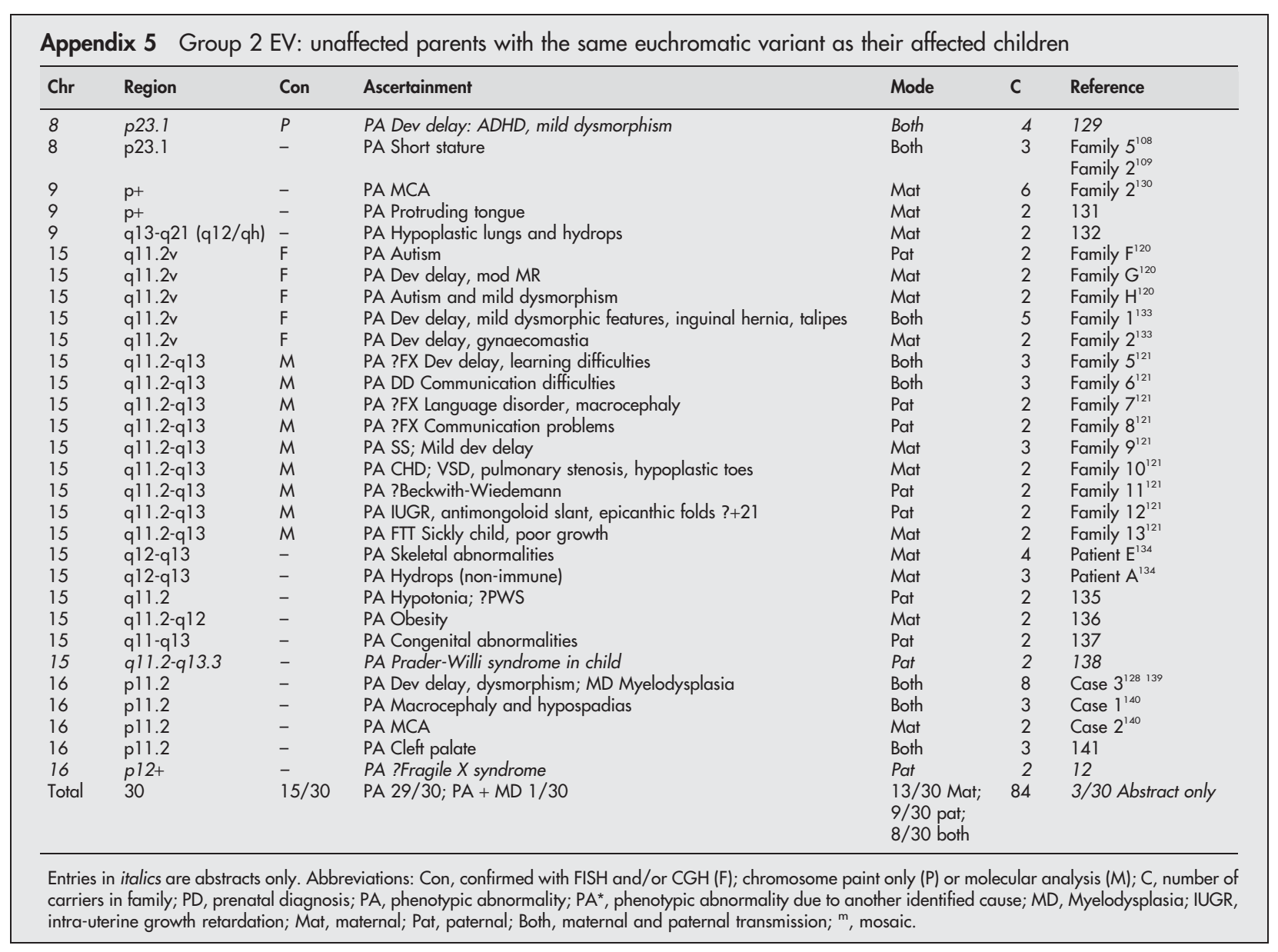

\begin{tabular}{|c|c|c|c|c|c|c|}
\hline \multicolumn{7}{|c|}{$\begin{array}{l}\text { Appendix } 6 \text { Group } 3 \text { EV: Affected parents with the same euchromatic variants as their } \\
\text { affected children }\end{array}$} \\
\hline $\mathrm{Chr}$ & Region & Con & Ascertainment & Mode & C & Ref \\
\hline 8 & p23.1 & $F, P$ & PA Mild dysmorphism & Mat & 3 & 142 \\
\hline 15 & $q 11-q 12$ & - & PA Short stature & Pat & 3 & 143 \\
\hline Total & 2 & 1 & PA $2 / 2$ & Mat 1; pat 1 & 6 & \\
\hline
\end{tabular}

